\title{
Effects of the Solution Treatment on Microstructural Evolution, Mechanical Properties, and Fracture Mechanism of Nickel-Based GH4099 Superalloy
}

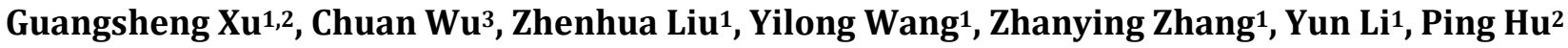 \\ ${ }^{1}$ Engineering Research Center of High-Performance Aerospace Materials and Devices, Universities of Shaanxi Province, Shaanxi \\ Polytechnic Institute, Xianyang, China \\ ${ }^{2}$ Xianyang Key Laboratory of New power and Intelligent Microgrid System, Xianyang, China \\ ${ }^{3}$ National-Local Joint Engineering Laboratory of Intelligent Manufacturing Oriented Automobile Die and Mould, Tianjin \\ University of Technology and Education, Tianjin, China \\ Email: xuguangshengss@163.com
}

How to cite this paper: $\mathrm{Xu}, \mathrm{G} . S ., \mathrm{Wu}, \mathrm{C}$. , Liu, Z.H., Wang, Y.L., Zhang, Z.Y., Li, Y. and $\mathrm{Hu}$, P. (2021) Effects of the Solution Treatment on Microstructural Evolution, Mechanical Properties, and Fracture Mechanism of Nickel-Based GH4099 Superalloy. Journal of Minerals and Materials Characterization and Engineering, 9, 566-589. https://doi.org/10.4236/jmmce.2021.96037

Received: September 24, 2021

Accepted: November 6, 2021

Published: November 9, 2021

Copyright $\odot 2021$ by author(s) and Scientific Research Publishing Inc. This work is licensed under the Creative Commons Attribution International License (CC BY 4.0).

http://creativecommons.org/licenses/by/4.0/ (c) (i) Open Access

\begin{abstract}
Grain growth, mechanical properties, and fracture mechanism of nickel-based GH4099 superalloy are investigated using heat treatments, tensile tests, optical microscopy (OM), and scanning electron microscopy (SEM) with energy dispersive X-ray spectroscopy (EDS). The OM observation shows that the matrix grains ( $\gamma$-grains) undergo an apparent growth during the solution treatment. The grain size diameter increases from 100 to $174 \mu \mathrm{m}$ when the solution temperature rises from $1100^{\circ} \mathrm{C}$ to $1160^{\circ} \mathrm{C}$ for $30 \mathrm{~min}$. When the holding time increases from 15 to $60 \mathrm{~min}$ at $1140^{\circ} \mathrm{C}$, the grain size diameter increases from 140 to $176 \mu \mathrm{m}$, indicating that the $\gamma$-grain growth is more sensitive to temperature than time. Standard deviation, $S_{v}$, and the grain size distribution are utilized to characterize the microstructural uniformity. To predict the grain size more accurately, we develop the grain growth kinetics and find that the growth index is close to 5 . The yield strength $\left(R_{\mathrm{p} 0.2}\right)$, tensile strength $\left(R_{\mathrm{m}}\right)$, and ductility $\left(A_{\mathrm{f}}\right)$ are also measured. It is found that the effect decreases in the order cooling rate, solution temperature, time. $R_{\mathrm{p} 0.2}$ reduces by $47 \%$ with the increase in the cooling rate from $1^{\circ} \mathrm{C}$ to $8000^{\circ} \mathrm{C} / \mathrm{min}$, while both strength and ductility exhibit little changes with time. The SEM results show that the fracture surfaces have typical mixed brittle and ductile characteristics when specimens are subjected to water quenching and air cooling. However, a complete brittle fracture occurs under furnace cooling conditions. The EDS analysis indicates that the brittle $\gamma^{\prime}\left(\mathrm{Ni}_{3} \mathrm{Ti}\right)$ phase precipitates around
\end{abstract}


the $\gamma$-grain boundary during the slow cooling process, which is the main factor yielding the complete brittle fracture. Finally, the optimal solution treatment scheme for the GH4099 superalloy is proposed-a temperature of $1140^{\circ} \mathrm{C}$ for $30 \mathrm{~min}$ followed by air cooling.

\section{Keywords}

Microstructural Evolution, Mechanical Properties, Fracture Mechanism, GH4099 Nickel-Based Superalloy

\section{Introduction}

GH4099 is a typical nickel-based superalloy, which is strengthened mainly by a solid solution of chromium ( $\mathrm{Cr}$ ), tungsten (W), molybdenum (Mo), and cobalt (Co), and second phase precipitation of $\gamma^{\prime}\left(\mathrm{Ni}_{3}(\mathrm{Al}, \mathrm{Ti})\right), \gamma^{\prime \prime}\left(\mathrm{Ni}_{\mathrm{x}} \mathrm{Nb}\right), \delta\left(\mathrm{Ni}_{\mathrm{x}} \mathrm{Nb}\right)$, Laves phase, and carbides [1] [2]. GH4099 superalloy exhibits good high-temperature strength, excellent corrosion resistance, and high oxidation resistance. It has been widely used in aerospace engineering and thermal and nuclear power generation to manufacture structural components, such as turbine disks, blades, and engine shafts [2] [3].

As already well established, the mechanical properties of nickel-based superalloys are strongly dependent on their final microstructures, where fine and uniform microstructures are especially beneficial for the improvement of fatigue resistance and mechanical strength [4] [5] [6] [7]. In general, hot working and subsequent heat treatments effectively enhance nickel-based superalloys' microstructural and mechanical properties [8].

Different microstructural evolution mechanisms, such as work hardening, dynamic recovery, and recrystallization, may occur during hot working, which have a significant effect on the final microstructures [9]. After hot working, an appropriate heat treatment scheme is necessary to induce microstructural changes, improve the mechanical properties, and remove the residual stress and microdefects [5]. However, final microstructures may be altered and deteriorated if the heat treatments are not properly selected. For instance, when a nickel-based superalloy was solution-treated at a relatively high temperature, the $\gamma, \gamma^{\prime}$ phase and carbides may precipitate, and microstructural coarsening may occur, largely enhancing the strength and reducing the ductility and creep properties [10]. Moreover, the $\delta$ - and Laves phases can precipitate around grain boundaries of the matrix during a slow cooling stage, yielding micro-defects that act as crack nucleation sites. Therefore, it is necessary to investigate the microstructural evolution and mechanical properties of nickel-based superalloys under different heat treatments to obtain desired microstructures and properties of the nickel-based superalloy parts.

Many studies were performed to assess the microstructural evolution and mechanical properties of typical nickel-based superalloys. Mahboobeh et al. [11] 
studied the effect of the solution treatment on creep properties of Inconel-713C superalloy and found that the solution treatment at $1200^{\circ} \mathrm{C}$ for $1 \mathrm{~h}$ decreased creep rupture, while the effect is negligible in the case of aging at $930^{\circ} \mathrm{C}$ for $16 \mathrm{~h}$ due to the precipitation of $\mathrm{NbC}$ carbides and the coarsening of $\gamma^{\prime}$ particles. Zhao et al. [12] investigated the coarsening and age-hardening behavior of a novel nickel-based superalloy and showed that the alloy's microhardness decreased significantly with the aging temperature. Ceena et al. [8] explored the microstructural evolution and mechanical properties of Haynes 282 superalloy subjected to different heat treatments and determined good room temperature strength and ductility obtained by a standard two-step aging because of the presence of finegrain boundary carbides and intragranular $\gamma^{\prime}$ phase. In contrast, the strength and ductility were significantly reduced upon the solution treatment at $1120^{\circ} \mathrm{C}$ because of interconnected grain boundary carbides and coarse intragranular $\gamma^{\prime}$ phase. Chen et al. [13] reported that an annealing treatment could effectively improve the microstructural homogeneity due to the static recrystallization. Masoumi et al. [14] determined the kinetics of $\gamma^{\prime}$ size and volume fraction of an advanced nickel-based superalloy $\mathrm{AD} 730^{\mathrm{TM}}$ during solution treatment. The authors disclosed the underlying mechanisms and developed a model to describe the dissolution and coarsening processes. Mostafaei et al. [15] studied the effect of solution and aging treatments on the microstructural and mechanical properties of a nickel-based superalloy. They showed that intermetallic phases, such as $\mathrm{Ni}_{3} \mathrm{Nb}$ and $\mathrm{Ni}_{2}(\mathrm{Cr}, \mathrm{Mo})$, and carbides, such as $\mathrm{NbC}$ and $\mathrm{Cr}_{23} \mathrm{C}_{6}$, could form during the aging stage, simultaneously increasing micro-hardness and tensile strength and decreasing ductility.

Although many studies have been conducted to investigate the microstructural evolution and mechanical properties of nickel-based superalloys during heat treatments, the effect of solution conditions on the microstructural evolution, mechanical properties, and fracture mechanism of a GH4099 superalloy was not investigated in detail. Particularly, the intrinsic relationship between solution treatments, microstructural evolution, mechanical properties, and fracture mechanism is still elusive.

In this study, the solution treatments of a GH4099 superalloy at different temperatures, times, and cooling rates were conducted, followed by uniaxial tensile tests. The microstructural evolution was characterized by optical microscopy $(\mathrm{OM})$. The formed precipitates were analyzed by energy-dispersive X-ray spectroscopy (EDS), while the fracture surface was examined using scanning electron microscopy (SEM). The mechanical properties, such as yield strength, tensile strength, and failure elongation, were determined. The effect of solution conditions on the microstructural evolution, mechanical properties, and fracture mechanism was discussed, and the optimum solution temperature, holding time, and cooling method of the GH4099 superalloy were identified. This study aims to provide an experimental basis for optimizing heat treatment schemes toward desired microstructures and final properties for thin-walled complex components of GH4099 superalloy. 


\section{Materials and Experiments}

GH4099 superalloy (Manufactured By WST) used in the present work consisted (in wt\%) of 0.06 carbon (C), 18.5 chromium (Cr), 4.0 molybdenum (Mo), 7.0 cobalt (Co), 6.0 tungsten (W), 2.3 aluminum (Al), 1.16 titanium (Ti), 0.14 other elements, and the nickel balance.

The GH4099 superalloy was subjected to various solution treatments followed by different cooling methods to assess the microstructural evolution. Detailed solution treatment procedures are shown in Table 1. After the solution treatments, standard tensile specimens, Figure 1, were cut from the solution-treated material using electrical discharge machining. The tensile tests were conducted on an MTS810 machine according to GR/T 228-2002 standard. Yield strength $\left(R_{\mathrm{p} 0.2}\right)$, tensile strength $\left(R_{\mathrm{m}}\right)$, and failure elongation $\left(A_{\mathrm{f}}\right)$ were determined. Two specimens were adopted to evaluate the properties for all solution conditions.

The microstructural evolution was examined using an OLYMPUS/PMG3 optical microscope. Metallographic samples were mechanically polished according to metallographic procedures and chemically etched with a solution of $5.0 \mathrm{ml}$ $\mathrm{H}_{2} \mathrm{SO}_{4}+80 \mathrm{ml} \mathrm{H}_{2} \mathrm{O}+150 \mathrm{ml} \mathrm{HCl}+20 \mathrm{~g} \mathrm{CuSO}_{4} \cdot 5 \mathrm{H}_{2} \mathrm{O}$, of those reagents are of analytical grade and deionized water. The fractography was performed using a Zeiss Sigma500 scanning electron microscope to identify the fracture mechanism of the GH4099 superalloy. The EDS analysis was used to characterize the precipitates at the grain boundaries.

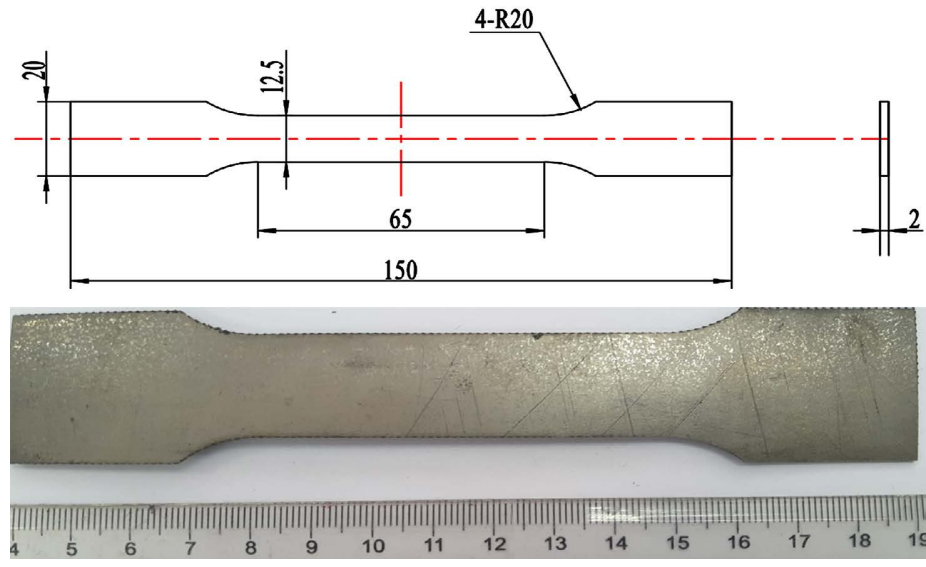

Figure 1. Schematic drawing of tensile specimen (Units: $\mathrm{mm}$ ).

Table 1. Aging treatment procedures.

\begin{tabular}{ccccc}
\hline \multirow{2}{*}{$\begin{array}{c}\text { Temperature } \\
\left({ }^{\circ} \mathrm{C}\right)\end{array}$} & 15 & 30 & 45 & 60 \\
\cline { 2 - 5 } 1100 & $\sqrt{ }$ & $\sqrt{ }$ & $\sqrt{ }$ & $\sqrt{ }$ \\
1120 & $\sqrt{ }$ & $\sqrt{ }$ & $\sqrt{ }$ & $\sqrt{ }$ \\
1140 & $\sqrt{ }$ & $\sqrt{ }$ & $\sqrt{ }$ & $\sqrt{ }$ \\
1160 & $\sqrt{ }$ & $\sqrt{ }$ & $\sqrt{ }$ & $\sqrt{ }$ \\
\hline
\end{tabular}




\section{Results and Discussion}

\subsection{Microstructural Evolution}

The initial microstructure of the GH4099 superalloy before the solution treatment is shown in Figure 2. The microstructure is homogeneous, with a grain diameter of approximately $30 \mu \mathrm{m}$.

The GH4099 superalloy was solution-treated at temperatures from $1100^{\circ} \mathrm{C}$ to $1160^{\circ} \mathrm{C}$ for $30 \mathrm{~min}$, followed by air cooling. At the holding stage, the size and distribution of the $\gamma$-phase grains change with time, which can directly determine the mechanical properties of superalloy. Thus, it is important to investigate the microstructural evolution under different solution treatments [14]. The optical micrographs of the material, Figures 3(a)-(d), indicate that the microstructure is very sensitive to solution temperature. Comparing to the initial structure, the microstructure becomes coarse, i.e., the grains grow rapidly at higher solution treatment temperatures. The grain size increases from $100 \mu \mathrm{m}$ at $1100^{\circ} \mathrm{C}$ to $174 \mu \mathrm{m}$ at $1160^{\circ} \mathrm{C}$. Some small grains are locally dispersed along the grain boundaries, and they become increasingly small until they disappear, indicating that relatively large grains grow at the cost of these small grains. When the solution temperature increases to $1120^{\circ} \mathrm{C}$ (Figure $3(\mathrm{~b})$ ), the size of matrix grains becomes large. However, the grain size varies little with a further time increase (Figure 3(c) and Figure 3(d)), indicating that the growth rate is slow at a fairly high temperature. This tendency has also been observed in the work of Chen et al. [5].

The fraction of grains with a size smaller than 10 or $200 \mu \mathrm{m}$ decreases gradually with temperature, and the grain size becomes nearly equal to the average value. The microstructures become increasingly uniform with temperature. It is generally considered that grain growth is a thermal activation process controlled by atom diffusion. The grain growth process can be described as follows:

$$
\Delta r=v \Delta t
$$

where $\Delta r$ is the increment of diameter during $\Delta t, v$ is grain boundary migration that can be written as follows:

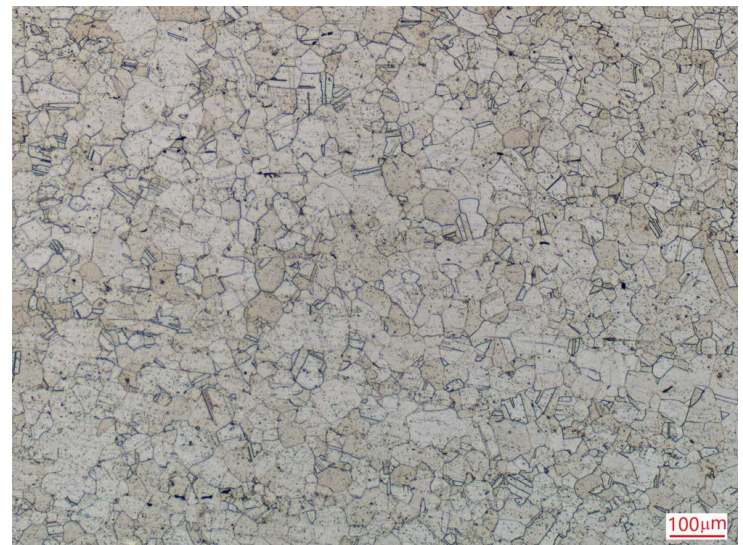

Figure 2. Initial microstructure of the GH4099 superalloy before the solution treatment. 

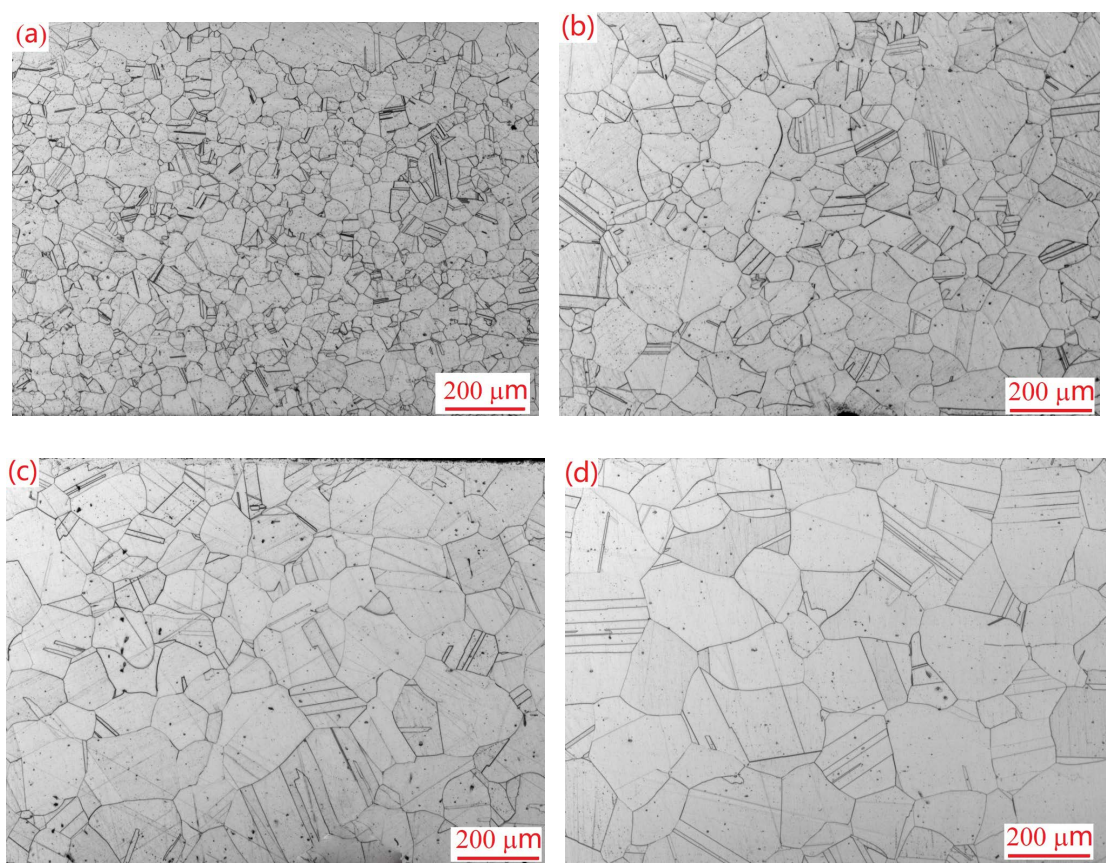

Figure 3. Microstructural evolution of the GH4099 superalloy solution-treated at temperatures of (a) 1100, (b) 1120, (c) 1140, and (d) 1140 for $30 \mathrm{~min}$.

$$
v=M_{0} \exp \left(-\frac{Q_{\mathrm{act}}}{k T}\right) P
$$

where $M_{0}$ and $k_{\mathrm{B}}$ are material constants, $Q_{\text {act }}$ is the apparent activation energy of grain boundary migration, and $P$ is the driving force for grain growth. Equation (2) implies that high annealing temperatures can promote the grain boundary migration rate. Thus, the grains become noticeably coarse at relatively high annealing temperatures. Figure 4 shows the microstructural evolution of the GH4099 superalloy solution treated at $1140^{\circ} \mathrm{C}$ for different times. The grain size does not change significantly compared to that in Figure 3. The average grain diameter increases from 140 to $176 \mu \mathrm{m}$ for a time interval from 15 to $60 \mathrm{~min}$ at $1140^{\circ} \mathrm{C}$, respectively.

The variation of microstructure uniformity (MU) with the solution treatment time is depicted in Figure 5. The MU is represented by the standard deviation $\left(S_{v}=\sqrt{\frac{1}{N} \sum_{i=1}^{N}\left(d_{i}-\bar{d}\right)^{2}}\right)$ of the average $\gamma$-phase grain size. Figure 5(a) shows that the MU decreases when the time is less than $45 \mathrm{~min}$, but it begins to increase at longer times, indicating that the microstructure becomes nonuniform, so coarsening or abnormal grain growth takes place. Apparently, large grains appear in Figures 3(b)-(d). Figure 5(b) shows the MU variation with temperature, i.e., it decreases rapidly with a temperature increase from $1100^{\circ} \mathrm{C}$ to $1120^{\circ} \mathrm{C}$ but remains almost constant with a further temperature increase.

The size distribution $(G(d))$ of the $\gamma$-phase grains under different solution conditions is shown in Figure 6 and Figure 7 where $G(d)=N(d, \Delta d) / N_{\text {total }}, d$ is the individual grain diameter, and $N(d, \Delta d)$ represents the number of the grains 

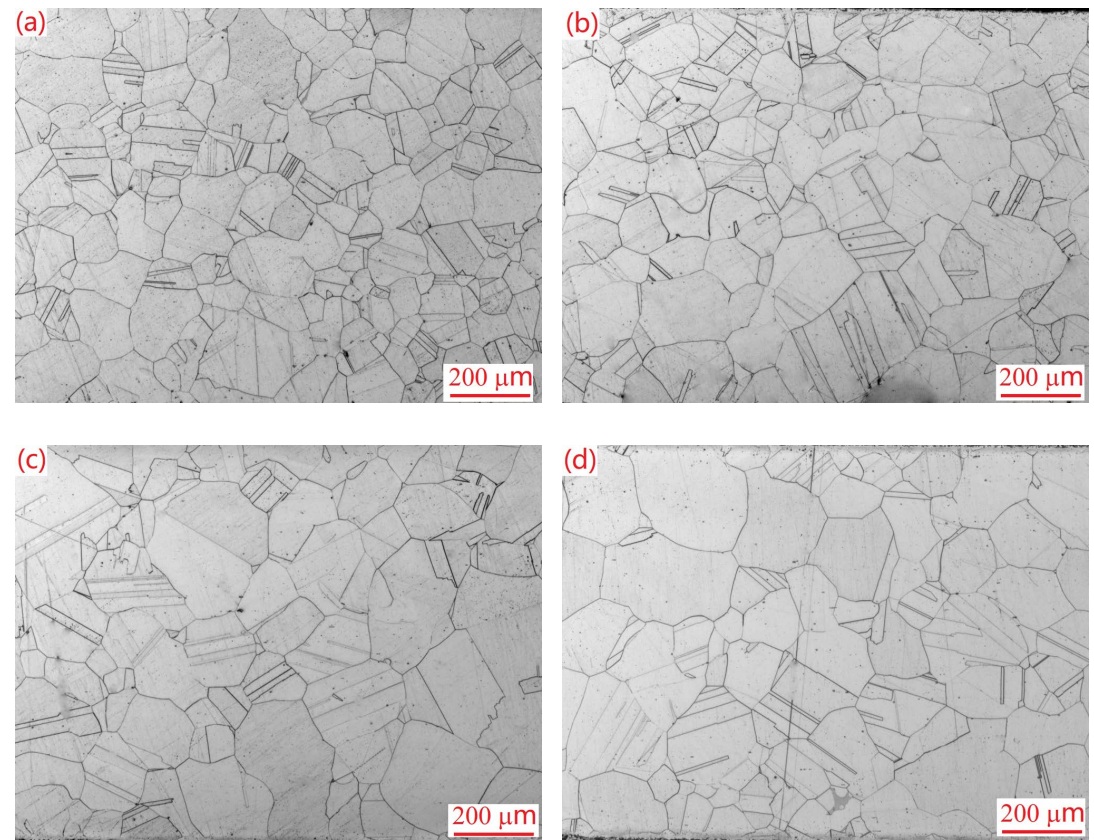

Figure 4. Microstructural evolution of the GH4099 superalloy solution-treated at $1140^{\circ} \mathrm{C}$ for (a) 15, (b) 30, (c) 45, and (d) $60 \mathrm{~min}$.

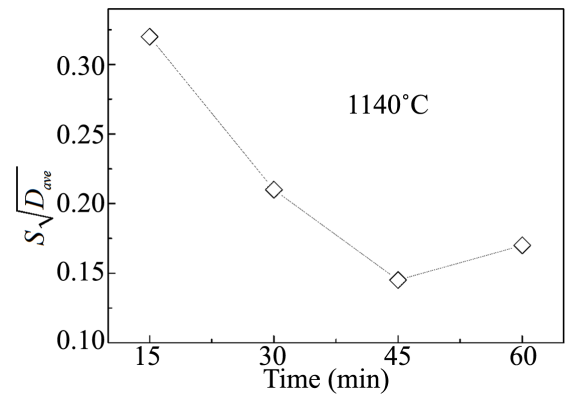

(a)

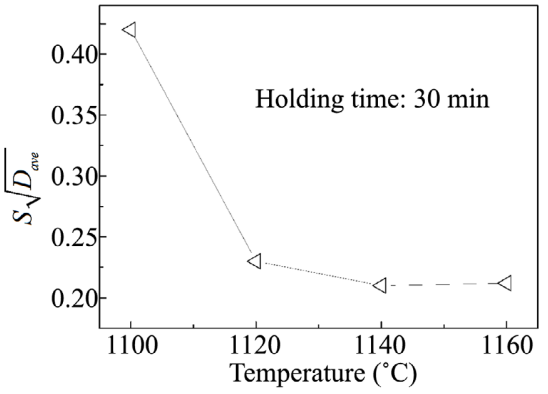

(b)

Figure 5. Variation of microstructural uniformity with (a) solution time and (b) temperature.

in a range of $d \pm \Delta d$ with $\Delta d=20$. The size distribution is sensitive to solution time. In Figure 7(a), the fraction of grains with the size in a range of $140-200$ $\mathrm{mm}$ is very small. The fraction of large grains and the average grain size increase with solution time, as shown in Figure 7(b). Figure 7(c) and Figure 7(d) represent the grain size distribution at a solution time of 30, 45 and $60 \mathrm{~min}$, respectively. The microstructure becomes more uniform, and the fraction of grains with a size close to the average value is large.

\subsection{Grain Growth Kinetics}

The main theoretical approach to modeling grain coarsening or Ostwald ripening was developed by Lifshitz and Slozov [16] and Wagner [17] (LSW theory), who predicted that the average grain radius $r$ increases with time $t$ according to the following relationship: 


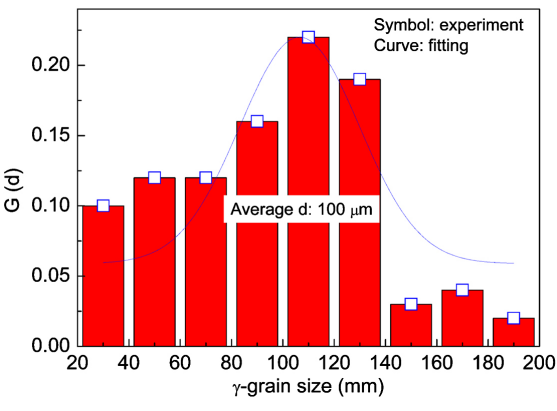

(a)

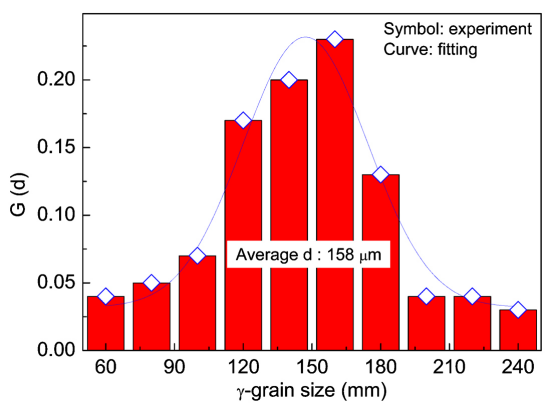

(c)

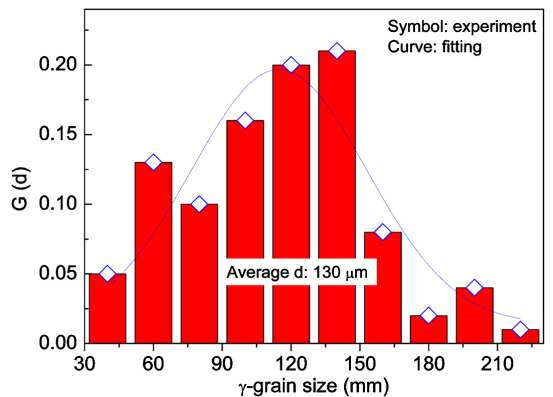

(b)

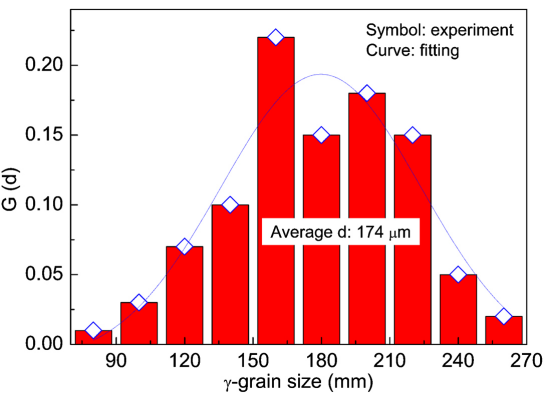

(d)

Figure 6. Grain size distribution of $\gamma$-phase at (a) $1100^{\circ} \mathrm{C}$, (b) $1120^{\circ} \mathrm{C}$, (c) $1140^{\circ} \mathrm{C}$, and (d) $1160^{\circ} \mathrm{C}$ for $30 \mathrm{~min}$.

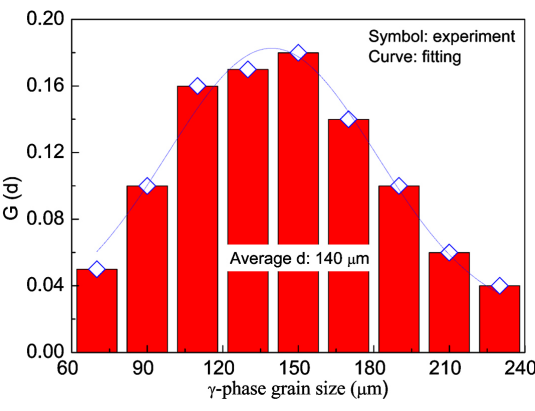

(a)

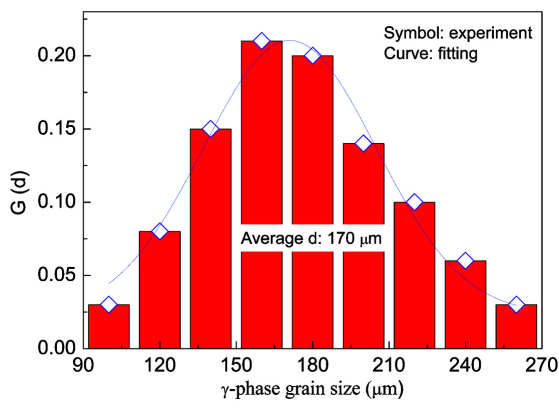

(c)

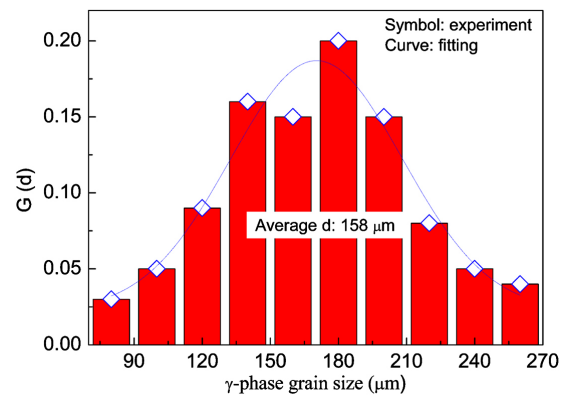

(b)

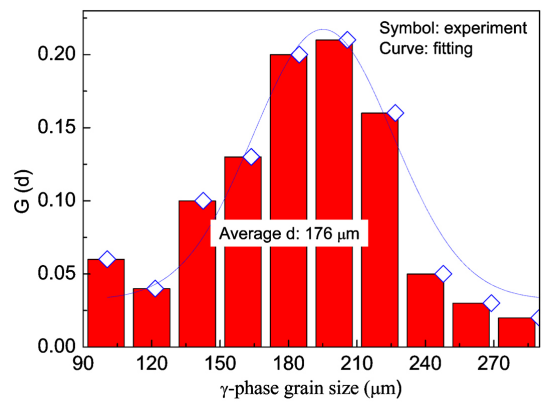

(d)

Figure 7. Grain size distribution of $\gamma$-phase at $1140^{\circ} \mathrm{C}$ for (a) 15 , (b) 30, (c) 45, and (d) 60 $\min$.

$$
r^{n}-r_{0}^{n}=K_{\text {grow }} t=K_{0} \exp \left(-\frac{Q_{\text {act }}}{R T}\right) t
$$


where $r$ and $r_{0}$ are the average grain radius and the initial value, respectively. $K_{\text {grow }}$ is coarsening rate constant, $K_{0}$ is material constant, $R$ is gas constant, and $T$ is the absolute temperature. $n$ is the coarsening index, representing different coarsening mechanisms. The parameter $n$ can be 5, 4, 3, or 2 depending on the coarsening mechanism: diffusion via dislocation cores $(n=5)$, along grain boundaries $(n=4)$, through the lattice $(n=3)$, or across a particle-matrix interface $(n=2)$ [18] [19] [20]. The $n$ value needs to be determined experimentally to investigate the coarsening mechanism of the GH4099 superalloy. The $n$ at different temperatures could be deduced by plotting the functional form of $r^{n}-r_{0}^{n}$ $v s$. $t$ for various values of $n$, as shown in Figure 8 . At $1100^{\circ} \mathrm{C}$, when $n$ is equal to 5 (see Figure 8(a)), the fitting curve is close to being a line; moreover, the correlation coefficient (COE) and slope error of the fitting line are $0.998 \%$ and $2.1 \%$, respectively, which means that the value of $n=5$ could satisfy a linear relationship. Similarly, at $1120^{\circ} \mathrm{C}$ (Figure $8(\mathrm{~b})$ ), $1140^{\circ} \mathrm{C}$ (Figure $8(\mathrm{c})$ ) and $1160^{\circ} \mathrm{C}$ (Figure 8(d)), the values of $n$ are close to 5.2, 5.2, and 5.1, respectively, assuming a linear relationship between $r^{n}-r_{0}^{n}$ and $t$.

The $n$ value at temperatures from $1100^{\circ} \mathrm{C}$ to $1160^{\circ} \mathrm{C}$ is close to 5 . Thus, the grain coarsening process of the GH4099 superalloy is considered to be controlled by solute diffusion through the dislocation cores. According to Equation (3), the value $K_{0} \exp \left(-Q_{\text {act }} / R T\right)$ is equal to the slope of the fitting line, and the $Q_{\text {act }}$ value is assumed to be the same at these temperatures. Thus, $Q_{\text {act }}$ can be deduced as $311.7 \mathrm{~kJ} / \mathrm{mol}$. The calculated value is higher than the reported activation energies for the $\gamma^{\prime}$ coarsening in a Ni matrix $(240-270 \mathrm{~kJ} / \mathrm{mol})$ [12] [14] [18].

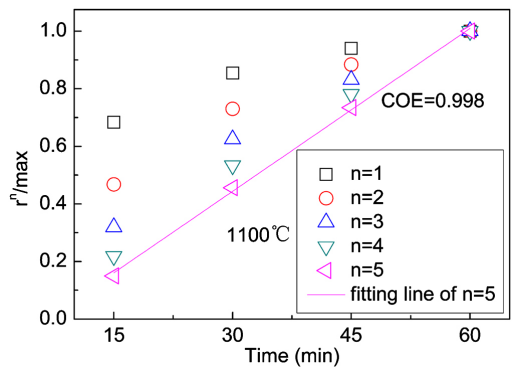

(a)

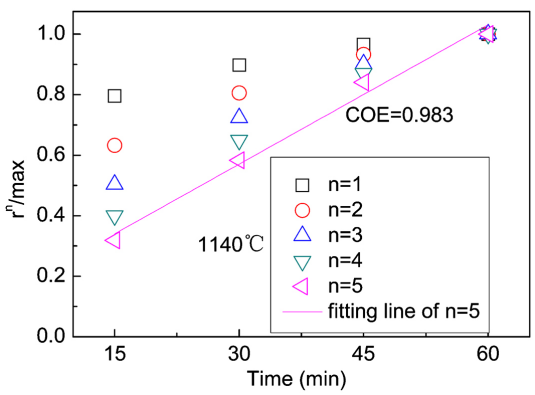

(c)

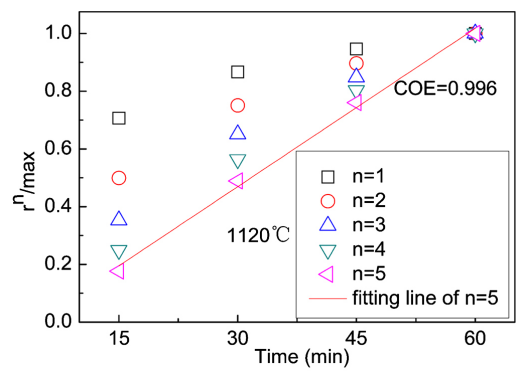

(b)

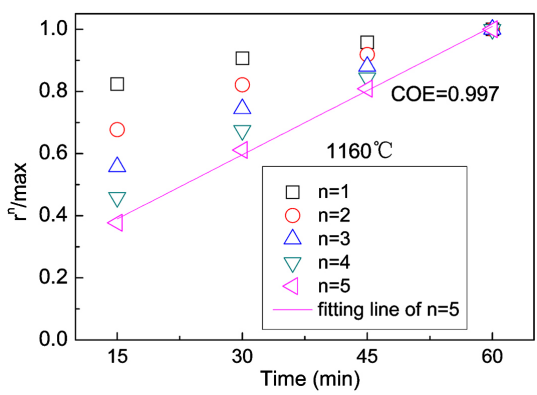

(d)

Figure 8. Linear relationship between $r^{n}-r_{0}^{n}$ and $t$ at temperatures of (a) $1100^{\circ} \mathrm{C}$, (b) $1120^{\circ} \mathrm{C}$, (c) $1140^{\circ} \mathrm{C}$, and (d) $1160^{\circ} \mathrm{C}$. 


\subsection{Mechanical Properties}

The mechanical properties of the GH4099 superalloy solution-treated at different conditions were tested, and the corresponding values, such as $R_{\mathrm{p} 0.2}, R_{\mathrm{m}}$, and $A_{\mathrm{f}}$, are listed in Table 2. The solution temperature has a significant effect on strength and ductility. The strength $\left(R_{\mathrm{p} 0.2}\right.$ and $\left.R_{\mathrm{m}}\right)$ decreases with the solution temperature, while ductility exhibits an opposite trend. The $R_{\mathrm{p} 0.2}$ value decreases from 399 to $298 \mathrm{MPa}$ with an increase in solution temperature from $1100^{\circ} \mathrm{C}$ to $1160^{\circ} \mathrm{C}, R_{\mathrm{m}}$ decreases from 863 to $743 \mathrm{MPa}$, while $A_{\mathrm{f}}$ increases from $58 \%$ to $73 \%$, as shown in Figure 9(a).

Many factors may contribute to the strength reduction during the solution treatment. They include dislocation annihilation, $\gamma$-grain growth, $\gamma^{\prime}$ coarsening, and an increase in solid solubility. In this study, there is no deformation before or after the heat treatment. Thus, no dislocations are produced in the GH4099 samples, so the effect of dislocation annihilation on the strength reduction is
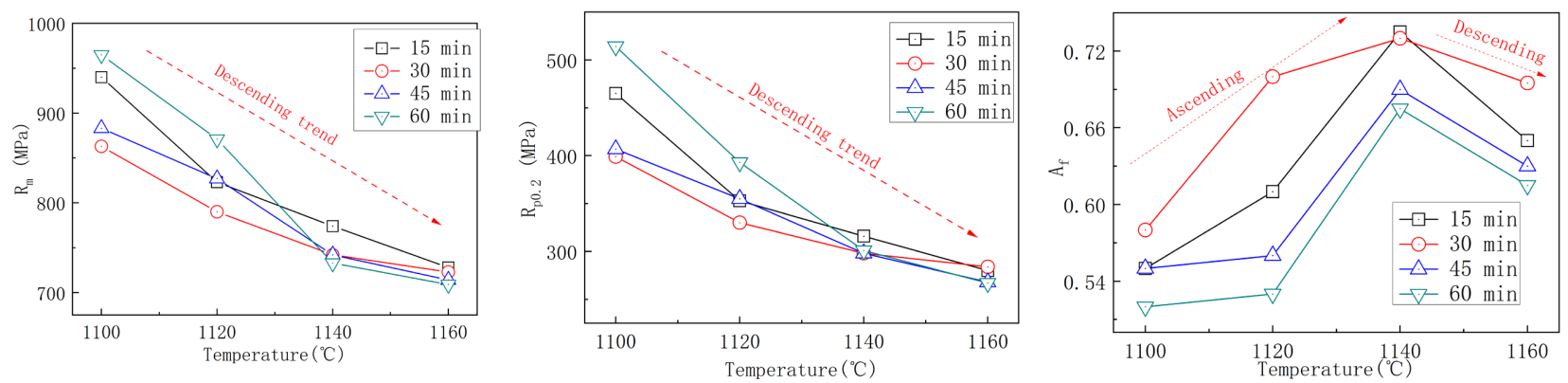

(a)
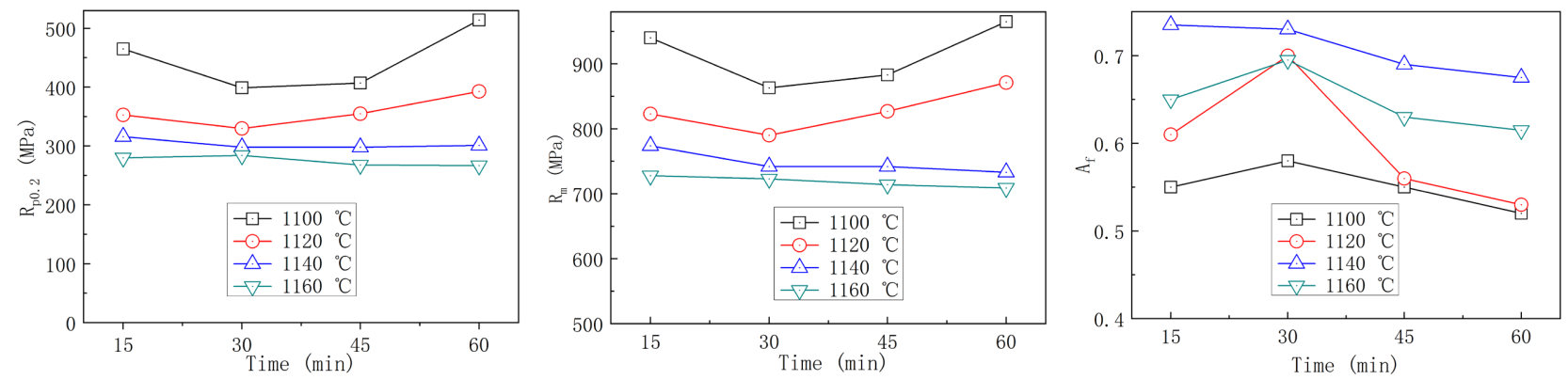

(b)

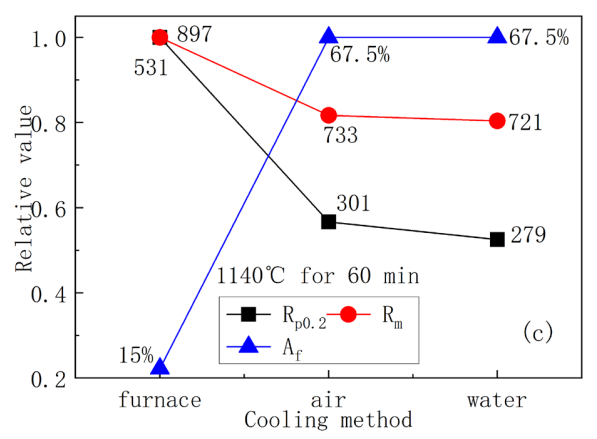

(c)

Figure 9. Variation of strength and ductility with (a) solution temperature, (b) time, and (c) cooling method. 
Table 2. Tensile properties $\left(R_{\mathrm{p} 0.2} / R_{\mathrm{m}} / A_{\mathrm{f}}\right)$ of $\mathrm{GH} 4099$ at different temperatures and times followed by air cooling.

\begin{tabular}{ccccc}
\hline \multirow{2}{*}{$\begin{array}{c}\text { Temperature } \\
\left({ }^{\circ} \mathrm{C}\right)\end{array}$} & 15 & 30 & 45 & 60 \\
\cline { 2 - 5 } & $465 / 940 / 55 \%$ & $399 / 863 / 58 \%$ & $407 / 883 / 56 \%$ & $514 / 965 / 52 \%$ \\
1100 & $353 / 823 / 61 \%$ & $330 / 790 / 70 \%$ & $355 / 827 / 55 \%$ & $393 / 871 / 53 \%$ \\
1120 & $316 / 774 / 73.5 \%$ & $298 / 742 / 73 \%$ & $298 / 742 / 69 \%$ & $301 / 733 / 67.5$ \\
1140 & $280 / 728 / 65 \%$ & $284 / 743 / 69.5 \%$ & $268 / 714 / 63 \%$ & $267 / 709 / 61.5$ \\
\hline 1160 & & & & \\
\hline
\end{tabular}

negligible. The grain sizes of $\mathrm{g}$ and $\gamma^{\prime}$ phases increase with the solution temperature. The effect of $\mu$

$$
\sigma=\sigma_{0}+\frac{k_{\mathrm{y}}}{\sqrt{d_{\mathrm{m}}}}
$$

where $s_{0}$ is the yield strength of a single crystal, $k_{\mathrm{y}}$ is the Hall-Petch coefficient (a value of $750 \mathrm{MPa} \mathrm{mm}^{1 / 2}$ used in many works for nickel-based superalloy) [21] [22], and $d_{\mathrm{m}}$ is the average grain diameter. Thus, the stress reduction caused by grain growth can be expressed as follows:

$$
\Delta \sigma_{\mathrm{GBS}}=k_{\mathrm{y}}\left(\frac{1}{\sqrt{\left.d_{\mathrm{m}}\right|_{T_{1}}}}-\frac{1}{\sqrt{\left.d_{\mathrm{m}}\right|_{T_{2}}}}\right) \quad\left(T_{2}>T_{1}\right)
$$

where $\Delta \sigma_{\mathrm{GBS}}$ is the stress reduction, $\left.d_{\mathrm{m}}\right|_{T_{2}}$ and $\left.d_{\mathrm{m}}\right|_{T_{1}}$ are average sizes at solution temperatures of $T_{2}$ and $T_{1}$, respectively. The average grain diameter increases from 100 to $174 \mu \mathrm{m}$ when the solution temperature increases from $1100^{\circ} \mathrm{C}$ to $1160^{\circ} \mathrm{C}$, so the yield strength reduction is calculated to be about $40 \mathrm{MPa}$. The Hall-Petch effect contribution to the total reduction of $R_{\mathrm{p} 0.2}$ is $40 \%$. The variation of solid solubility with solution temperature has a significant effect on strength reduction. At $1100^{\circ} \mathrm{C}$, the solid solubility of $\mathrm{W}, \mathrm{Mo}$, and Co is relatively low, causing a severe lattice distortion of $\gamma$-phase and resulting in significant solidsolution strengthening. Thus, the values of $R_{\mathrm{p} 0.2}$ and $R_{\mathrm{m}}$ are relatively high. The solid solubility of these elements in the $\gamma$-matrix increases with the solution temperature. As a result, the lattice distortion is weaker, and the effect of the solid-solution strengthening diminishes. Finally, the strength of the GH4099 superalloy reduces as well.

The effect of solution time on the strength and ductility is also addressed, Figure 9(b). Comparing with Figure 9(a), the variation of $R_{\mathrm{p} 0.2}, R_{\mathrm{m}}$, and $A_{\mathrm{f}}$ with time is very small. The reduction rates of $R_{\mathrm{p} 0.2}$ and $R_{\mathrm{m}}$ are only $4.7 \%$ and $5.2 \%$, respectively, and $A_{\mathrm{f}}$ retains nearly the same value of $70 \%$. This is because the GH4099 superalloy is solid-solution strengthened, and the solid solubility remains the same at a fixed temperature with increasing time. Moreover, the grain size of $\gamma$-phase exhibits a little change with time at a fixed temperature, so the effect of grain boundary strengthening on the strength and ductility is also small. 
Therefore, the values of $R_{\mathrm{p} 0.2}, R_{\mathrm{m}}$, and $A_{\mathrm{f}}$ nearly remain the same during the solution holding stage, although these values exhibit small fluctuations.

Figure 9 (c) depicts the significant change in $R_{\mathrm{p} 0.2}, R_{\mathrm{m}}$, and $A_{\mathrm{f}}$ with the cooling method. In furnace cooling, the values of $R_{\mathrm{p} 0.2}$ and $R_{\mathrm{m}}$ are 531 and $897 \mathrm{MPa}$, respectively, way larger than those in Figure 9(a) and Figure 9(b), while the $A_{\mathrm{f}}$ value is very small (only 15\%). When the cooling changes from furnace cooling (a cooling rate of $1^{\circ} \mathrm{C} / \mathrm{min}$ ) to air cooling (a cooling rate of $100^{\circ} \mathrm{C} / \mathrm{min}$ ) [23], both $R_{\mathrm{p} 0.2}$ and $R_{\mathrm{m}}$ decrease rapidly to 301 and $733 \mathrm{MPa}$, respectively, but $A_{\mathrm{f}}$ increases to $67.5 \%$. With a further increase in the cooling rate to $8000^{\circ} \mathrm{C} / \mathrm{min}$ in water quenching [23], strength and ductility fluctuate nearly remain the same. For the furnace cooling, a very slow cooling rate of $1{ }^{\circ} \mathrm{C} / \mathrm{min}$ can easily cause the precipitation of $\gamma^{\prime}$ phase $\left(\mathrm{Ni}_{3}(\mathrm{Al}, \mathrm{Ti})\right), \delta$ phase $\left(\mathrm{Ni}_{3} \mathrm{Nb}\right)$, and carbides along the $\gamma$-grain boundaries and coarsening [24]. Usually, these large precipitates are very hard and brittle. On the one hand, these hard phases/particles may play a vital role in locking or pinning dislocation motions during deformation, which results in the improvement of $R_{\mathrm{p} 0.2}$ and $R_{\mathrm{m}}$. On the other hand, due to the precipitation of these brittle phases in the zone of grain boundaries, an intense stress concentration could appear around these zones. Simultaneously, the binding force between neighboring grains becomes weaker, so the material becomes very brittle. Moreover, these hard and brittle particles act as nucleation sites and facilitate the crack propagation, yielding a brittle fracture and finally reducing ductility. The fracture morphology and composition analysis can support this conclusion, which will be discussed in the following section.

\subsection{Fracture Morphology and Mechanism}

\subsubsection{Effect of Solution Temperature}

The fracture surfaces of the tensile specimens are investigated using SEM to understand the effect of solution temperature on fracture behavior. As can be seen in Figure 10, the fracture surfaces show a mixed ductile and brittle fracture mode. All fracture surfaces are covered with dimples, still expressing some differences between them. In Figure 10 (a), when the solution temperature is $1100^{\circ} \mathrm{C}$, the fracture surface is flat, but some fine shallow dimples and facets can be observed. The ductility is good, and the corresponding elongation is $58 \%$.

As the solution temperature increases to $1120^{\circ} \mathrm{C}$, Figure $10(\mathrm{~b})$, the fracture surface exhibits some morphological ups and downs. The dimples are much deeper and nonuniform in size, and the area fraction of facets decreases compared to that in Figure 10(a). These phenomena indicate that the fracture mode gradually changes from mixed to a typical ductile fracture, which agrees with its better ductility of $70 \%$ elongation. However, some microvoids can be observed on the fracture surface. The solid solubility of alloy elements increases with the solution temperature, so higher amounts of elements can dissolve into the $\gamma$-phase, increasing their contents increase. This promotes the precipitation of the $\delta$ phase and carbides from the matrix during the cooling stage. Lin et al. [25] provided a detailed description in terms of the formation and development of 

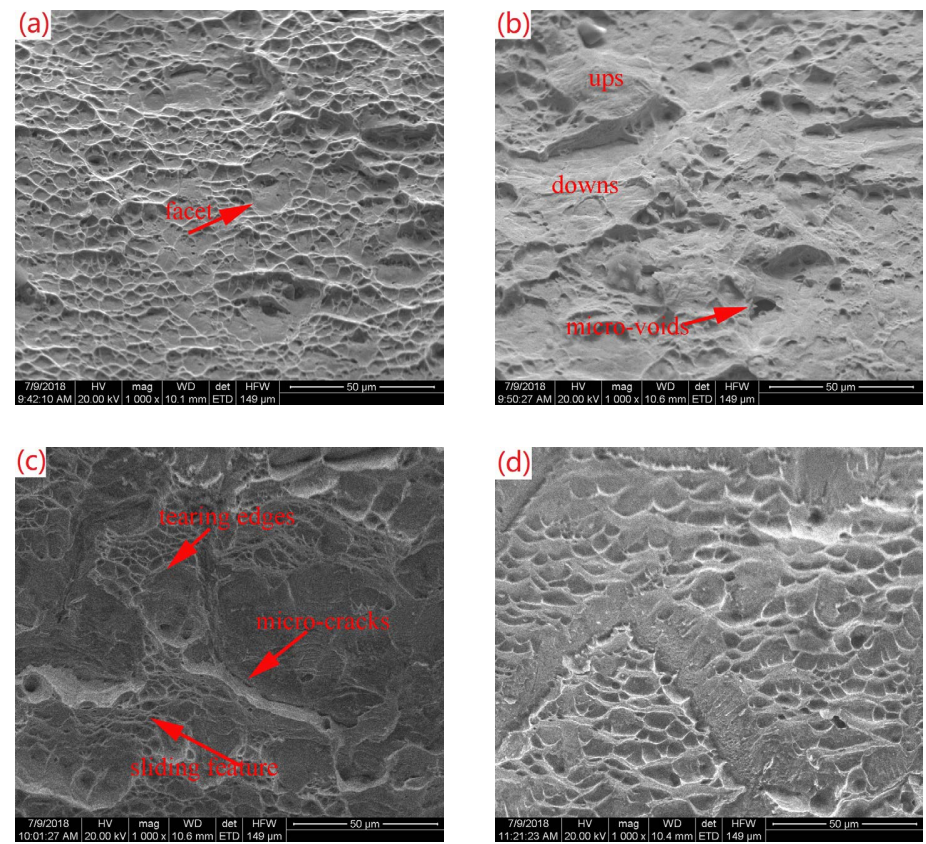

Figure 10. Fracture surfaces of the GH4099 superalloy specimens solution treated at (a) 1100 , (b) 1120 , (c) 1140 , and (d) $1160^{\circ} \mathrm{C}$ for $30 \mathrm{~min}$.

microvoids. Compared to the $\gamma$-phase, the $\delta$-phase, and carbides are relatively hard and brittle. These hard particles impede the dislocation motion during the deformation process, yielding the strain localization and stress concentration around them. As the stress reaches the bond strength of the $\gamma$-phase, $\delta$-phase, or carbides, or the breaking limit of $\delta$-phase and carbides, the microvoids nucleate. The microvoids begin to coalesce and extend in the tensile direction with further deformation.

As solution temperature increases to $1140^{\circ} \mathrm{C}$, Figure $10(\mathrm{c})$, large micro-cracks form due to the coalescence of adjacent small dimples in addition to some deep dimples and microvoids distributed on the fracture surface. Some tearing edges appear, and a big fracture step or blade type edge can be observed. Even bigger dimples appear on the fracture surface because of the dimple coalescence. Under such conditions, serpentine sliding features around the dimples become more apparent, i.e., the material experiences a certain degree of plastic deformation after the formation of dimples [25]. Particularly, the serpentine sliding features are getting more and more pronounced, Figure 10(d). The material exhibits a good combination of strength and ductility, consistent with its high values of $R_{\mathrm{p} 0.22}, R_{\mathrm{m}}$, and $A_{\mathrm{f}}$.

\subsubsection{Effect of Solution Time}

Figure 11 shows the effect of solution time on fracture behavior of the GH4099 superalloy. The fracture surfaces of specimens do not change significantly with the solution time. It indicates that the effect of solution time on fracture behavior is not significant compared to the solution temperature. The mixed fracture mode is dominant under these conditions. The fracture surfaces are covered by 

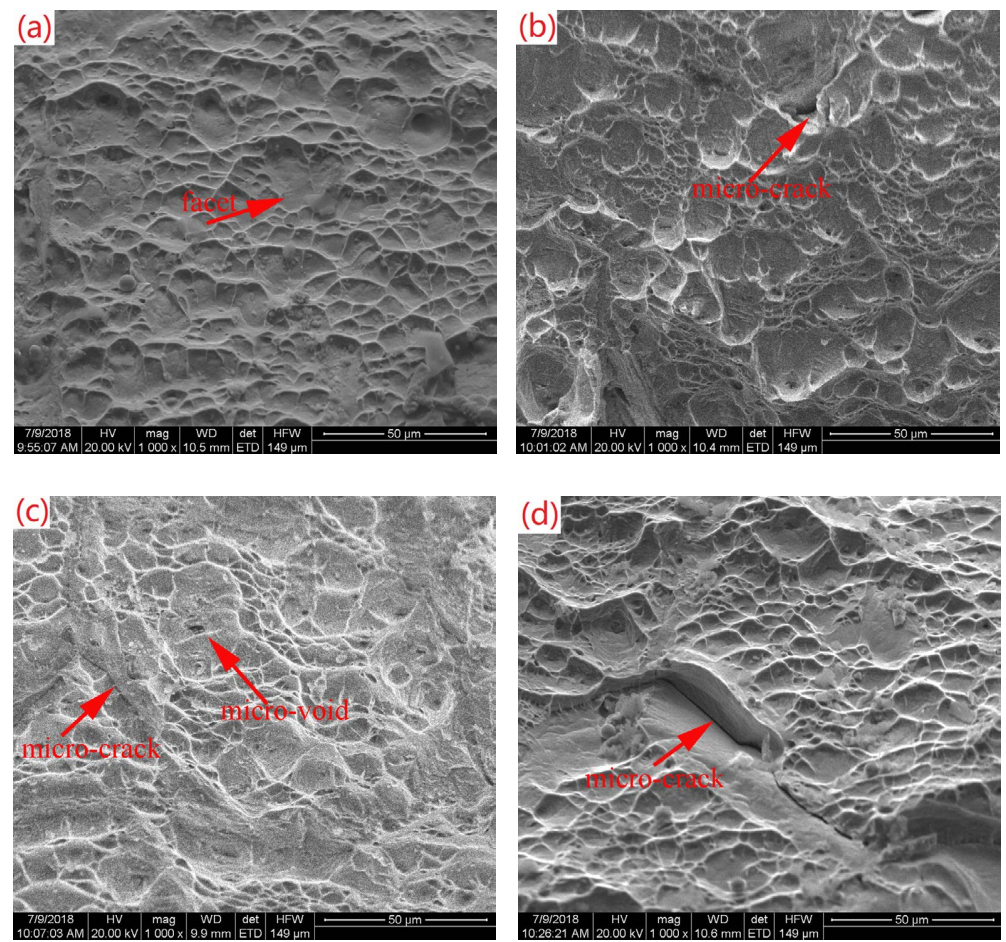

Figure 11. Fracture surfaces of the GH4099 superalloy specimens solution-treated at $1140^{\circ} \mathrm{C}$ for (a) 15 , (b) 30 , (c) 45 , and (d) $60 \mathrm{~min}$.

many shallow dimples and a few facets. As the solution time prolongs, Figure 11(b), many deep dimples become nonuniform in size compared to those at $1140^{\circ} \mathrm{C}$ for $15 \mathrm{~min}$, Figure 11(a). Apparent serpentine sliding features occur around the dimples, originating from the new sliding process on the free surface of dimples [23]. However, the intergranular facets are still visible. Some micro-cracks and microvoids appear on the surface, deteriorating the plastic deformation capability of the superalloy. Thus, the strength and ductility of the $\mathrm{GH} 4099$ superalloy solution treated at $1140^{\circ} \mathrm{C}$ for $30 \mathrm{~min}$ are close to those for 15 min, which is supported by the variation of $R_{\mathrm{p} 0.2}, R_{\mathrm{m}}$, and $A_{\mathrm{f}}$ values with the solution time in Figure 9(b). Dimples, serpentine sliding lines, some tearing edges, intergranular facets, micro-cracks, and voids are still distributed on the fracture surfaces with a further increase of solution time. It indicates the fracture mode exhibits a mixed brittle and ductile behavior. The change of the material plasticity with solution time is little.

\subsubsection{Effect of Cooling Method}

The effect of the cooling method on the fracture behavior is significant, Figures 12(a)-(c). The fracture behavior varies from a mixed brittle and ductile mode to a complete brittle mode. The specimens are water-quenched or cooled in air. Their fracture surfaces exhibit similar characteristics, such as deep dimples with different sizes, serpentine sliding lines, and intergranular facets. The values of $R_{\mathrm{p} 0.22}, R_{\mathrm{m}}$, and $A_{\mathrm{f}}$ after water quenching matched those after cooling in air. However, when the specimen is subjected to furnace cooling, the fracture surface is 

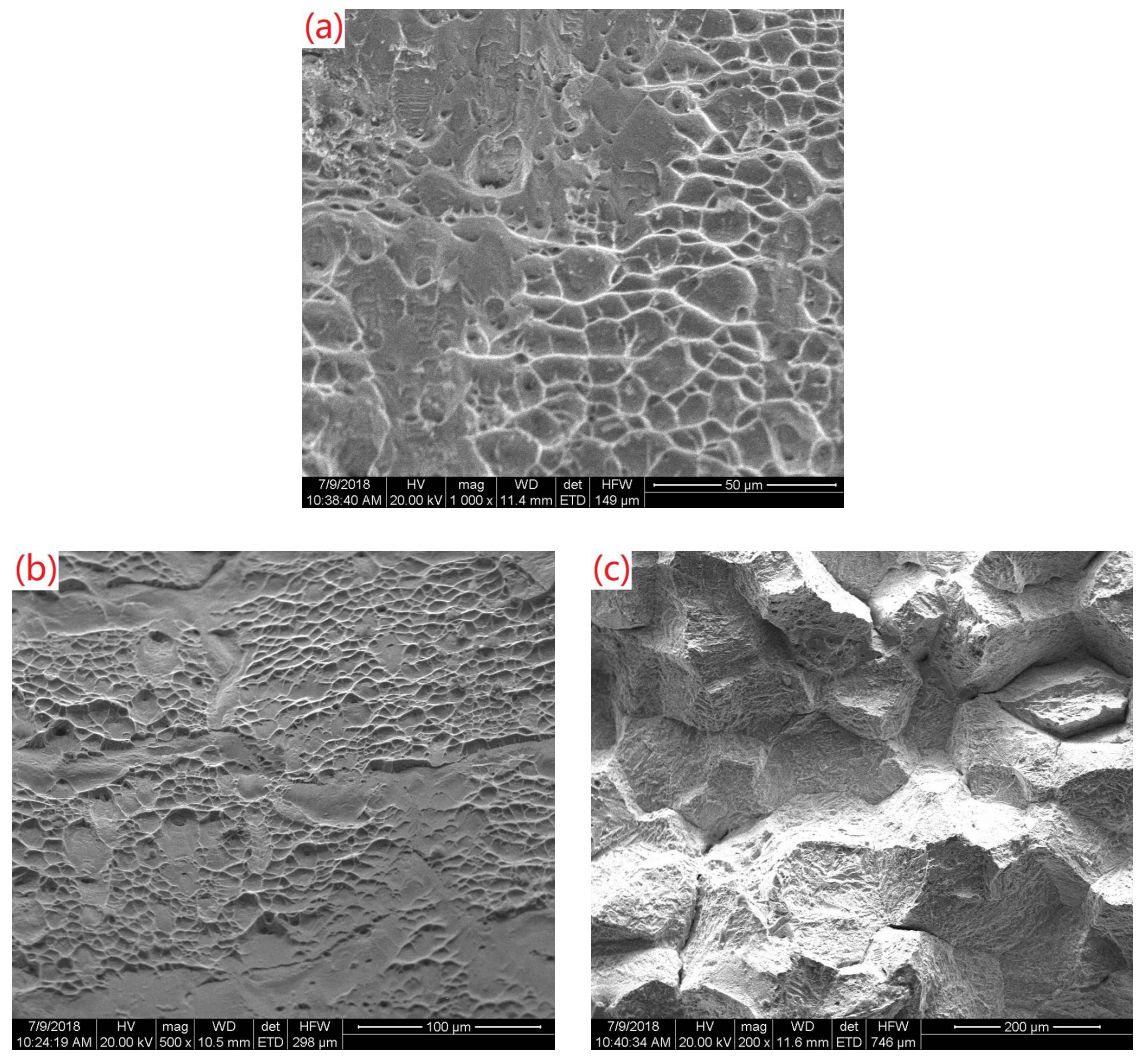

Figure 12. Fracture surfaces of the GH4099 superalloy specimens solution-treated at $1140^{\circ} \mathrm{C}$ for $60 \mathrm{~min}$ followed by (a) water quenching, (b) air cooling, and (c) furnace cooling.

completely different, showing a typical brittle intergranular fracture mode. The fracture surface is covered by intergranular facets without any dimples. Figure 12 (c) shows that the $\gamma$-phase grain size is very large and nearly exceeds $150 \mu \mathrm{m}$ because of the apparent growth or coarsening. Moreover, the grain boundaries of the $\gamma$-phase become very brittle, and the bonding strength decreases. The nickel-based superalloys' fracture behavior is directly dependent on the relative strength between grain interior and grain boundaries [25]-[30]. For the specimens subjected to furnace cooling, the cooling rate is very slow (about $1^{\circ} \mathrm{C} / \mathrm{min}$ ), and there is enough time for precipitation of various hard and brittle precipitates or carbides from the matrix phase. These hard and brittle particles pin or lock dislocations in the grain boundaries, yielding a high stress concentration. When the stress exceeds the bonding strength of grain boundaries, intergranular fracture occurs. In addition, these zones become preferential nucleation sites for micro-voids or micro-cracks due to the precipitates and carbides at the grain boundaries, which deteriorates the grain boundary strength. The coalescence of micro-voids and micro-cracks promotes the formation of cracks and subsequent propagation along grain boundaries with further plastic deformation.

Figure 13 shows the SEM micrographs of the GH4099 superalloy specimens subjected to different cooling methods to determine the precipitates or carbides in the grain boundaries. The SEM micrographs of the alloy subjected to water 

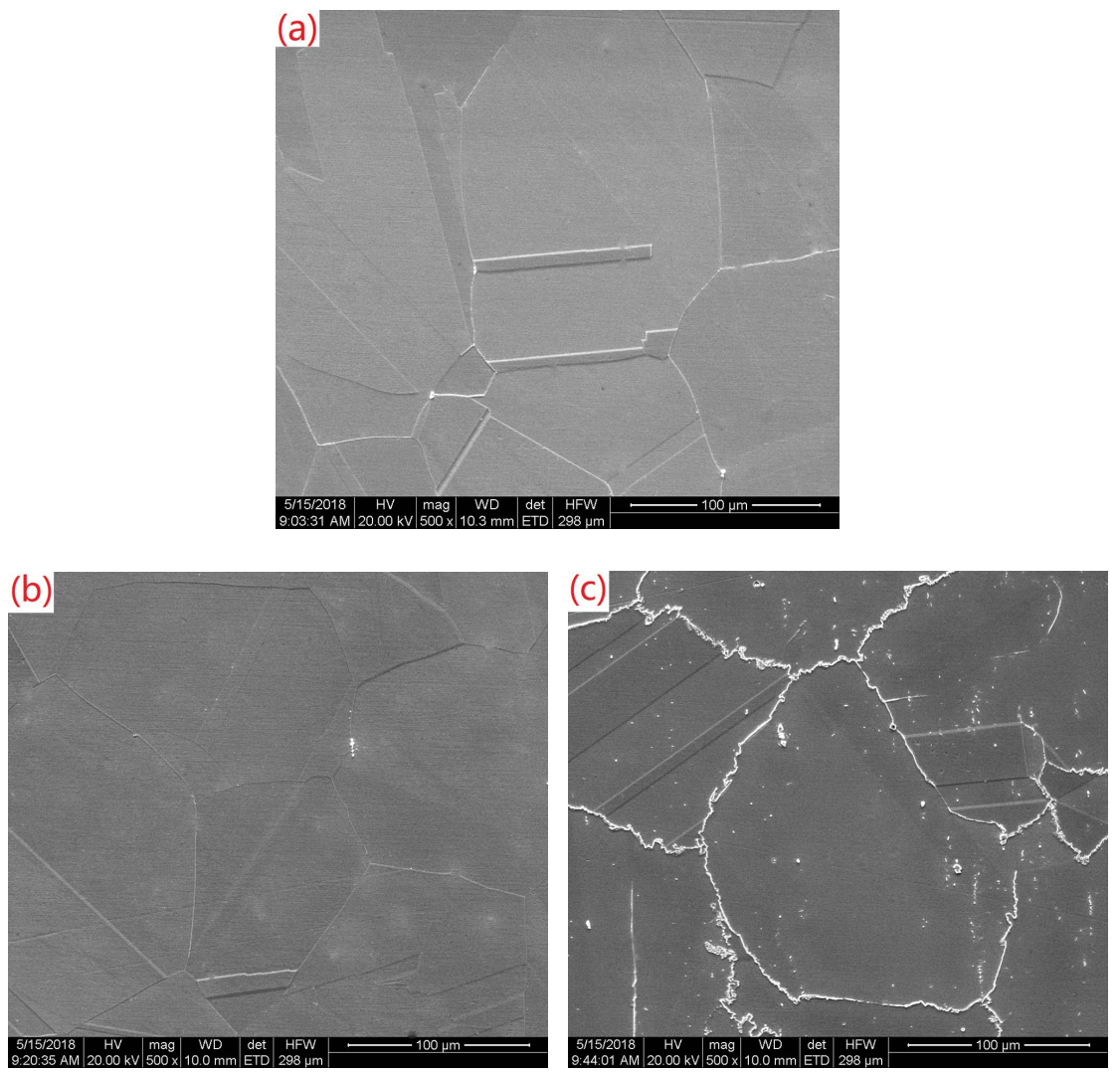

Figure 13. SEM micrographs of the GH4099 superalloy specimens solution-treated at $1140^{\circ} \mathrm{C}$ for $60 \mathrm{~min}$, followed by (a) water quenching, (b) air cooling, and (c) furnace cooling.

quenching and air cooling are shown in Figure 13(a) and Figure 13(b), respectively. The microstructures have similar characteristics. For instance, the gray grain boundaries are relatively straight and clean, and the grain size is in a range of $150-170 \mu \mathrm{m}$. However, in furnace cooling, Figure 13(c), the microstructure is different from that in Figure 13(a) and Figure 13(b), exhibiting serrated grain boundaries where bright precipitation phases appear.

The EDS analysis is used to detect the chemical composition of the matrix, grain boundaries, and precipitates and calculate the weight percentage of each element in the alloy, Figures 14-16. Figure 14(a) and Figure 14(b) show the marked points in the matrix and grain boundaries, respectively. The matrix possesses the same alloy elements as the grain boundary zones. Moreover, the calculated average weight percentage at these points is close to that of the as-received material. It is indicated that there are no secondary phases, such as $\gamma^{\prime}$ $\left(\mathrm{Ni}_{3}(\mathrm{Al}, \mathrm{Ti})\right), \delta\left(\mathrm{Ni}_{3} \mathrm{Nb}\right)$, and carbides, precipitating from the matrix phase. The elemental distribution is relatively uniform. Similar results can be observed in Figure 15, where the GH4099 superalloy was subjected to air cooling. The matrix contains the same elements as the grain boundaries, and the detected weight percentages in the matrix and grain boundaries are close to those of the as-received material. 


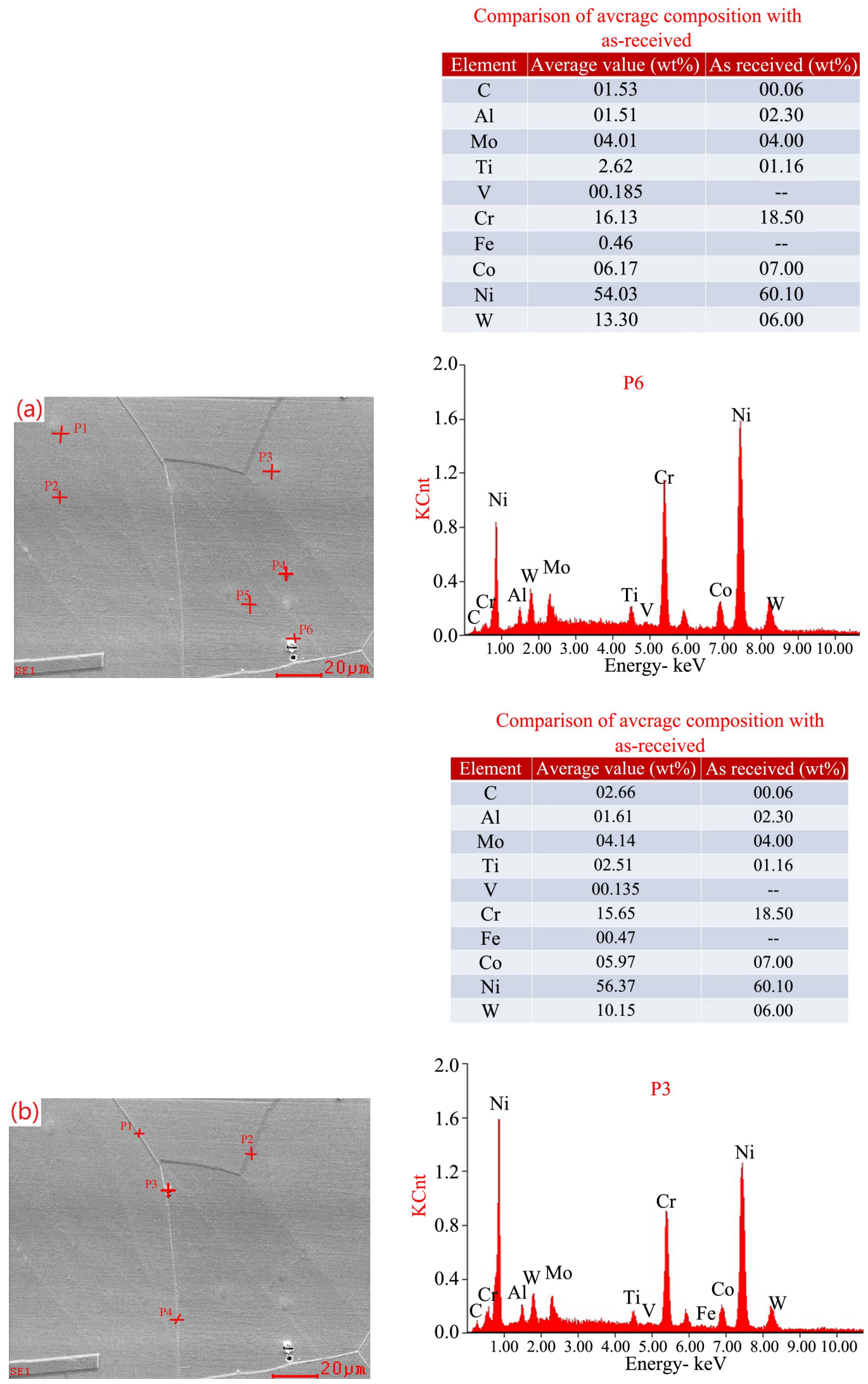

Figure 14. Elemental composition (in wt\%) of marked points in (a) matrix and (b) grain boundaries of the GH4099 superalloy specimens solution-treated at $1140^{\circ} \mathrm{C}$ for $60 \mathrm{~min}$ followed by water quenching. 

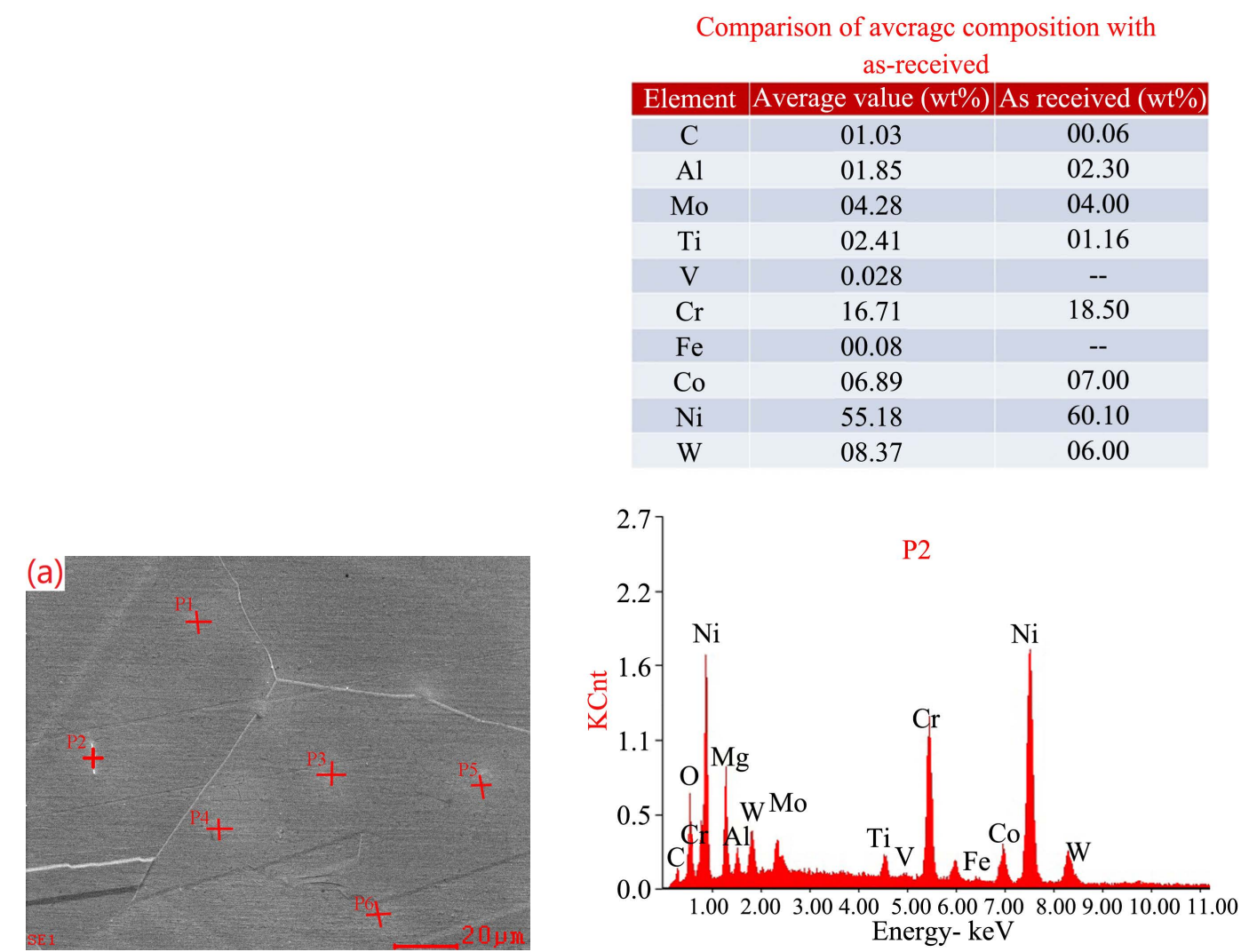

\section{Comparison of avcragc composition with} as-received

\begin{tabular}{|c|c|c|}
\hline Element & Average value $(\mathrm{wt} \%)$ & As received $(\mathrm{wt} \%)$ \\
\hline $\mathrm{C}$ & 00.83 & 00.06 \\
\hline $\mathrm{Al}$ & 01.26 & 02.30 \\
\hline $\mathrm{Mo}$ & 02.72 & 04.00 \\
\hline $\mathrm{Ti}$ & 01.58 & 01.16 \\
\hline $\mathrm{V}$ & 0 & -- \\
\hline $\mathrm{Cr}$ & 17.30 & 18.50 \\
\hline $\mathrm{Fe}$ & 0 & -- \\
\hline $\mathrm{Co}$ & 05.44 & 07.00 \\
\hline $\mathrm{Ni}$ & 57.18 & 60.10 \\
\hline $\mathrm{W}$ & 07.01 & 06.00 \\
\hline
\end{tabular}
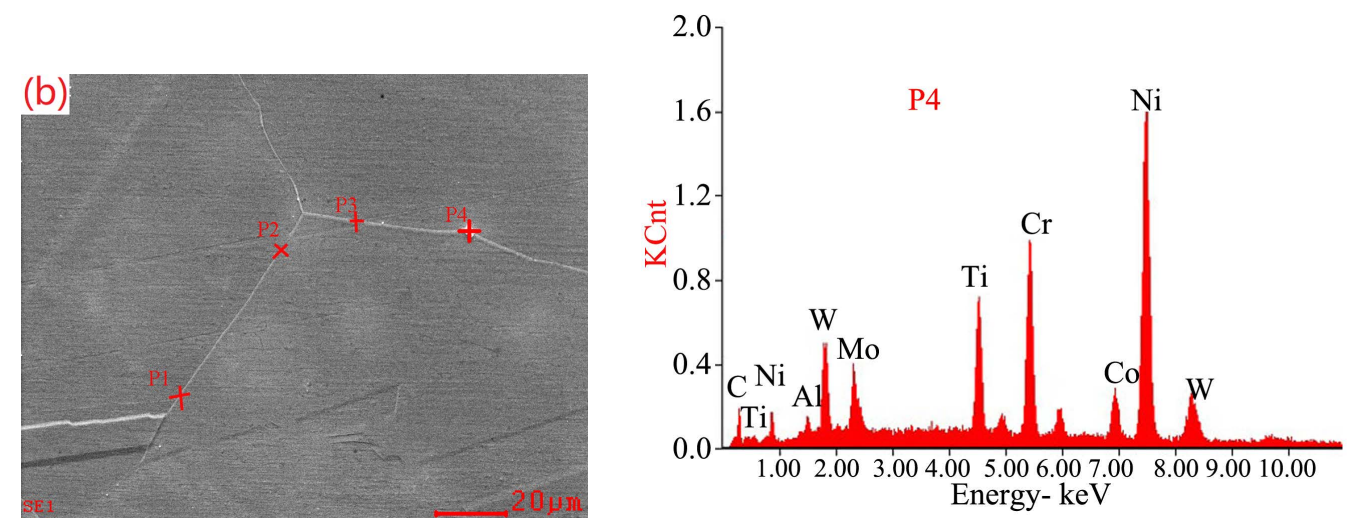

Figure 15. Elemental composition (in wt\%) of marked points in (a) matrix and (b) grain boundaries of the GH4099 superalloy specimens solution-treated at $1140^{\circ} \mathrm{C}$ for $60 \mathrm{~min}$ followed by air cooling. 
Comparison of average

\section{\begin{tabular}{|l|l|l|} 
Element & Average value $(w t \%)$ & As received $(w t \%)$
\end{tabular}}

\begin{tabular}{|c|c|c|}
\hline $\mathrm{C}$ & 00.43 & 00.06 \\
\hline $\mathrm{N}$ & 00.22 & -- \\
\hline $\mathrm{Al}$ & 00.37 & 02.30 \\
\hline $\mathrm{Mo}$ & 10.14 & 04.00 \\
\hline $\mathrm{Ti}$ & 25.93 & 01.16 \\
\hline $\mathrm{Cr}$ & 05.69 & 18.50 \\
\hline $\mathrm{Co}$ & 02.05 & 07.00 \\
\hline $\mathrm{Ni}$ & 45.98 & 60.10 \\
\hline $\mathrm{W}$ & 09.19 & 06.00 \\
\hline
\end{tabular}

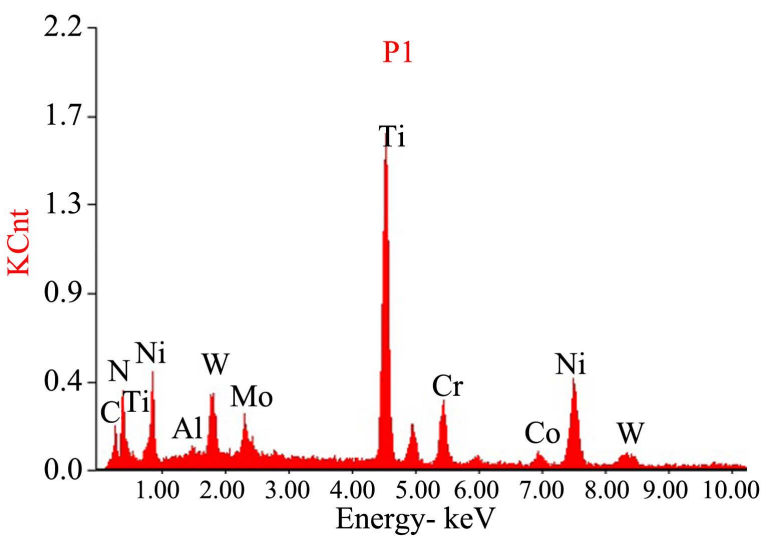

Comparison of avcragc composition with as-received

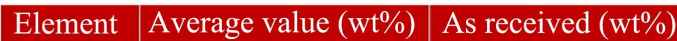

\begin{tabular}{|c|c|c|}
\hline $\mathrm{C}$ & 0.54 & 00.06 \\
\hline $\mathrm{Al}$ & 1.63 & 02.30 \\
\hline $\mathrm{Mo}$ & 4.15 & 04.00 \\
\hline $\mathrm{Ti}$ & 27.64 & 01.16 \\
\hline $\mathrm{Cr}$ & 17.7 & 18.50 \\
\hline $\mathrm{Fe}$ & 0 & -- \\
\hline $\mathrm{Co}$ & 2.87 & 07.00 \\
\hline $\mathrm{Ni}$ & 22.1 & 60.10 \\
\hline $\mathrm{W}$ & 11.7 & 06.00 \\
\hline
\end{tabular}
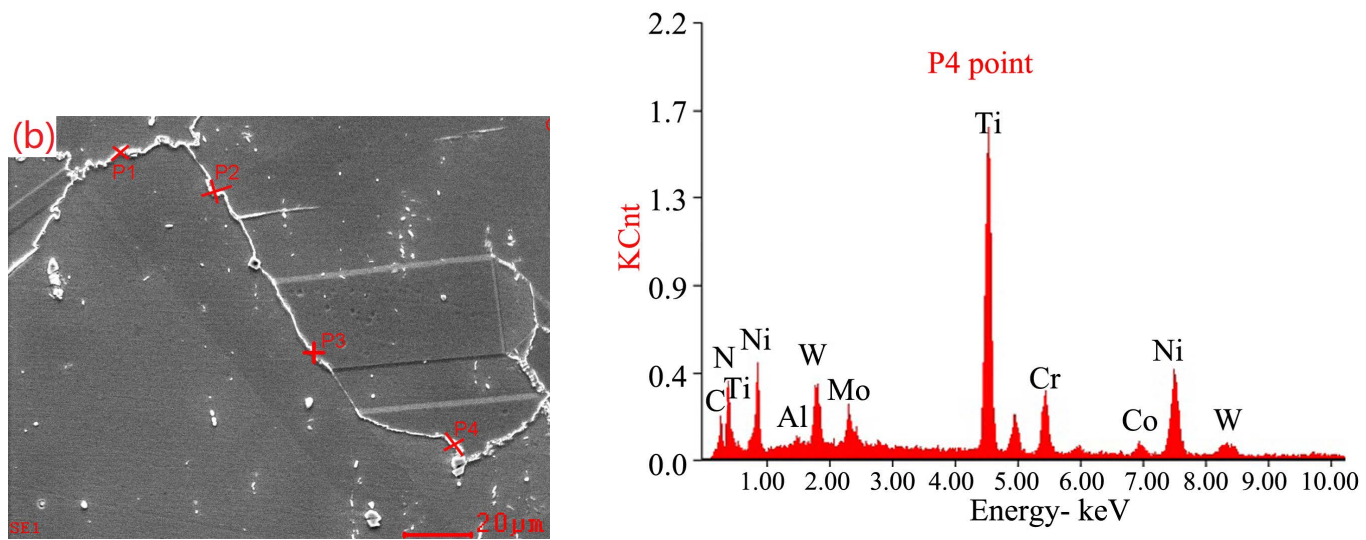
Comparison of avcragc composition with

as-received

\begin{tabular}{|c|c|c|}
\hline Element & Average value $(w t \%)$ & As received $(w t \%)$ \\
\hline $\mathrm{C}$ & 00.66 & 00.06 \\
\hline $\mathrm{Al}$ & 01.49 & 02.30 \\
\hline $\mathrm{Mo}$ & 03.72 & 04.00 \\
\hline $\mathrm{Ti}$ & 01.46 & 01.16 \\
\hline $\mathrm{Cr}$ & 16.89 & 18.50 \\
\hline $\mathrm{Fe}$ & 00.27 & -- \\
\hline $\mathrm{Co}$ & 06.24 & 07.00 \\
\hline $\mathrm{Ni}$ & 58.07 & 60.10 \\
\hline $\mathrm{W}$ & 12.19 & 06.00 \\
\hline
\end{tabular}
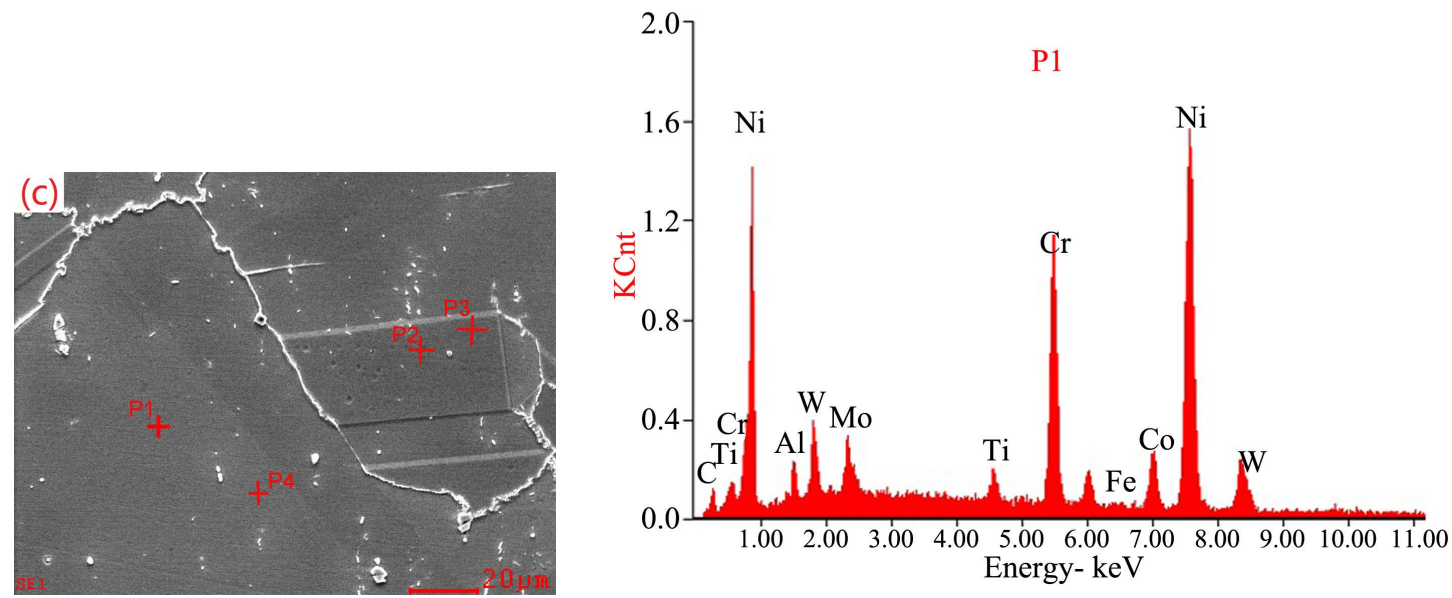

Figure 16. Elemental composition (in wt\%) of marked points in (a) bright precipitates in matrix, (b) bright precipitates at grain boundaries, and (c) in the matrix phase without precipitates of the $\mathrm{GH} 4099$ superalloy specimens solution-treated at $1140^{\circ} \mathrm{C}$ for $60 \mathrm{~min}$ followed by air cooling.

However, for specimens subjected to furnace cooling, Figure 16, the EDS results are different from those in Figure 14 and Figure 15. The bright phases in the matrix and grain boundaries are marked and detected, Figure 16(a) and Figure 16(b). The average weight percentage of $\mathrm{Ti}$ in the bright precipitate phases is much higher than that in the as-received material (1.16 wt\%). The average weight percentages of $\mathrm{Ti}$ in the precipitated phase in the matrix and grain boundaries are about $25.93 \%$ and $27.64 \%$, respectively. Figure 16 (c) shows the marked points in the matrix without bright precipitates. The detected element types and weight percentages are close to the as-received material. Thus, it can be deduced that the bright phase may be the $\gamma^{\prime}$-phase, which often appears in superalloys with a small amount of $\mathrm{Al}$ and $\mathrm{Ti}$. The $\gamma^{\prime}$ phase yields precipitation hardening of the matrix, which in turn reduces the grain boundary strength. Moreover, the precipitates act as potential nucleation sites for cracks, further deteriorating the grain boundary strength. Thus, the grain boundaries become relatively weak, and the cracks propagate along the grain boundaries, causing brittle intergranular fractures. 


\section{Conclusions}

The effects of solution treatments on the microstructural evolution, mechanical properties, and fracture mechanism of the GH4099 superalloy were studied in detail. The main conclusions can be drawn as follows:

1) The average grain size increased from 100 to $174 \mu \mathrm{m}$ with a temperature increase from $1100^{\circ} \mathrm{C}$ to $1160^{\circ} \mathrm{C}$. The $S_{\mathrm{v}}$ value decreased with temperature and time, implying that the microstructural morphology gradually tended to be uniform and the grain size was approaching the average value. Still, the $S_{\mathrm{v}}$ value gradually increased when holding time was more than $45 \mathrm{~min}$, originating from the $\gamma$-grain coarsening or abnormal growth.

2) The influence on the mechanical properties $\left(R_{\mathrm{p} 0.2}, R_{\mathrm{m}}\right.$, and $\left.A_{\mathrm{f}}\right)$ decreased in the order cooling rate, temperature, time. The values of $R_{\mathrm{p} 0.2}$ and $R_{\mathrm{m}}$ were 531 and $897 \mathrm{MPa}$, respectively, when the GH4099 was subjected to furnace cooling (with a cooling rate of $1^{\circ} \mathrm{C} / \mathrm{min}$ ), but the $A_{\mathrm{f}}$ was only $15 \%$. When the material was subjected to water quenching (with a cooling rate of $8000^{\circ} \mathrm{C} / \mathrm{min}$ ) and air cooling (with a cooling rate of $100^{\circ} \mathrm{C} / \mathrm{min}$ ), the $R_{\mathrm{p} 0.2}$ value was in a range from 280 to $301 \mathrm{MPa}$, and $R_{\mathrm{m}}$ is in a range from 720 to $730 \mathrm{MPa}$, while $A_{\mathrm{f}}$ rapidly increased to $67.5 \%$.

3) The SEM observation showed that the fracture surfaces changed from a mixed fracture mode (ductile and brittle) to a complete brittle mode when the cooling method changed from water quenching or air cooling to furnace cooling. The EDS analysis indicated the presence of $\gamma^{\prime}\left(\mathrm{Ni}_{3}(\mathrm{Al}, \mathrm{Ti})\right)$ precipitates in the $\gamma$-grain boundaries in the furnace cooling stage, which was the main reason for the brittle fracture.

4) Finally, an optimal solution treatment scheme ( 1140 for ${ }^{\circ} \mathrm{C} 30 \mathrm{~min}$ followed by air cooling) was proposed for the GH4099 superalloy.

\section{Acknowledgements}

The authors would like to acknowledge the support from National Natural Science Foundation of China (No.51904242 and No. 52075386) and Doctoral Fund Project of Shaanxi Polytechnic Institute (ZK18-09).

The authors would like to express their gratitude to EditSprings (https://www.editsprings.com/) for the expert linguistic services provided.

\section{Conflicts of Interest}

The authors declare no conflicts of interest regarding the publication of this paper.

\section{References}

[1] Xia, L.C. (2014) Research on Reasons for Bursting of GH4099 Alloy Bar. Special Steel Technology, 20, 41-46.

[2] Lin, Y.C., Yang, H., Xin, Y.C. and Li, C.Z. (2018) Effects of Initial Microstructures on Serrated Flow Features and Fracture Mechanisms of a Nickel-Based Superalloy. 
Materials Characterization, 144, 9-21. https://doi.org/10.1016/j.matchar.2018.06.029

[3] He, G.D., Lin, Y.C., Chen, S.M., Chen, J., Wen, X.D. and Chen, M.X. (2015) Effect of Pre-Treatment on Hot Deformation Behavior and Processing Map of an Aged Nickel-Based Superalloy. Journal of Alloys and Compounds, 649, 1075-1084. https://doi.org/10.1016/j.jallcom.2015.07.213

[4] He, D.G., Lin, Y.C., Wang, L.H., Wu, Q. and Zu, Z.H. (2019) Influences of PrePrecipitated $\delta$ Phase on Microstructures and Hot Compressive Deformation Features of a Nickel-Based Superalloy. Vacuum, 161, 242-250. https://doi.org/10.1016/j.vacuum.2018.12.043

[5] Lin, Y.C., Yang, H. and Li, L. (2017) Effects of Solutionizing Cooling Processing on $\mathrm{Ni}_{3} \mathrm{Nb}$ Phase and Work Hardening Characteristics of a Ni-Fe-Cr-Base Superalloy. Vacuum, 144, 86-93. https://doi.org/10.1016/j.vacuum.2017.07.025

[6] Chen, X.M., Lin, Y.C. and Wu, F. (2017) EBSD Study of Grain Growth Behavior and Annealing Twin Evolution after Full Recrystallization in a Nickel-Based Superalloy. Journal of Alloys and Compounds, 724, 198-207.

https://doi.org/10.1016/j.jallcom.2017.07.027

[7] Lin, Y.C. and Chen, X.M. (2011) A Critical Review of Experimental Results and Constitutive Descriptions for Metals and Alloys in Hot Working. Materials \& Design, 32, 1733-1759. https://doi.org/10.1016/j.matdes.2010.11.048

[8] Lin, Y.C., Deng, J., Jiang, Y.Q., Wen, D.X. and Liu, G. (2014) Effects of Initial $\delta$ Phase on Hot Tensile Deformation Behaviors and Fracture Characteristics of a Typical Ni-Based Superalloy. Materials Science and Engineering. A, 598, 251-262. https://doi.org/10.1016/j.msea.2014.01.029

[9] Anbarasan, N., Bikash, K.G., Prakash, S., Muthukumar, P., Oyyaravelu, R., John, K.F., Kumar, R. and Jerome, S. (2018) Effect of Heat Treatment on the Microstructure and Mechanical Properties of Inconel 718. Materials Today. Proceedings, 5, 7716-7724. https://doi.org/10.1016/j.matpr.2017.11.448

[10] Shi, H., Chen, K., Shen, Z., Wu, J.Q., Dong, X.P., Zhang, L.T. and Shan, A.D. (2015) Twin Boundary Characters Established during Dynamic Recrystallization in a Nickel Alloy. Materials Characterization, 110, 52-59. https://doi.org/10.1016/j.matchar.2015.10.007

[11] Ceena, J., Christer Persson, P. and Magnus, H.C. (2017) Influence of Heat Treatment on the Microstructure and Tensile Properties of Ni-Base Superalloy Haynes 282. Materials Science and Engineering. A, 679, 520-530. https://doi.org/10.1016/j.msea.2016.10.048

[12] Mahboobeh, A., Armin, M., Sama, S., Mohammad, A., Mehdi, S. and Mohammad, H.R. (2018) Effects of Solutioning and Ageing Treatments on Properties of Inconel-713C Nickel-Based Superalloy under Creep Loading. Materials Science and Engineering: $A, 711,195-204$. https://doi.org/10.1016/j.msea.2017.11.038

[13] Zhao, S.Q., Xie, X.S., Smith, G.D. and Patel, S.J. (2004) Gamma Prime Coarsening and Age-Hardening Behaviors in a New Nickel Base Superalloy. Materials Letters, 58, 1784-1787. https://doi.org/10.1016/j.matlet.2003.10.053

[14] Chen, M.S., Zou, H.Z., Lin, Y.C., Li, B.H. and Yuan, Q.W. (2018) Effects of Annealing Parameters on Microstructural Evolution of a Typical Nickel-Based Superalloy during Annealing Treatment. Materials Characterization, 141, 212-222. https://doi.org/10.1016/j.matchar.2018.04.056

[15] Masoumi, F., Jahazi, M., Shahriari, D. and Cormier, J. (2016) Coarsening and Dissolution of $\gamma$ Precipitates during Solution Treatment of AD730 ${ }^{\mathrm{Tm}} \mathrm{Ni}$-Based Superalloy: Mechanisms and Kinetics Models. Journal of Alloys and Compounds, 658, 
981-995. https://doi.org/10.1016/j.jallcom.2015.11.002

[16] Mostafaei, A., Behnamian, Y., Krimer, Y.L., Stevens, E.L., Luo, J.L. and Chmielus, M. (2016) Effect of Solutionizing and Aging on the Microstructure and Mechanical Properties of Powder Bed Binder Jet Printed Nickel-Based Superalloy 625. Materials \& Design, 111, 482-491. https://doi.org/10.1016/j.matdes.2016.08.083

[17] Lifshitz, I.M. and Slyozov, V.V. (1961) The Kinetics of Precipitation from Supersaturated Solid Solutions. Journal of Physics and Chemistry of Solids, 19, 35-50. https://doi.org/10.1016/0022-3697(61)90054-3

[18] Wagner, C. (1961) Theorie der Alterung von Niederschlagen durch Umlosen (Ostwald-Reifung). Zeitschrift für Elektrochemie, 65, 581-591.

[19] Johnson, C.H., Richter, S.K., Hamilton, C.H. and Hoyt, J.J. (1999) Static Grain Growth in a Microduplex Ti-6Al-4V Alloy. Acta Materialia, 47, 23-29. https://doi.org/10.1016/S1359-6454(98)00341-3

[20] Wu, C., Yang, H., Li, H.W. and Yang, G.B. (2013) Primary Alpha Grain Coarsening Behavior of Ti-6Al-2Zr-1Mo-1V Alloy in the Alpha + Beta Two-Phase Field. Journal of Materials Engineering and Performance, 22, 2557-2566.

https://doi.org/10.1007/s11665-013-0537-8

[21] Campbell, C.E., Boettinger, W.J. and Kattner, U.R. (2002) Development of a Diffusion Mobility Database for Ni-Base Superalloys. Acta Materialia, 50, 775-792. https://doi.org/10.1016/S1359-6454(01)00383-4

[22] Hu, Y.L., Lin, X., Zhang, S.Y., Jiang, Y.M., Lu, X.F., Yang, H.O. and Huang, W.D. (2018) Effect of Solution Heat Treatment on the Microstructure and Mechanical Properties of Inconel 625 Superalloy Fabricated by Laser Solid Forming. Journal of Alloys and Compounds, 767, 330-344. https://doi.org/10.1016/j.jallcom.2018.07.087

[23] Kozar, R.W., Suzuki, A., Milligan, W.W., Schirra, J.J., Sacage, M.F. and Pollock, T.M. (2009) Strengthening Mechanisms in Polycrystalline Multimodal Nickel-Base Superalloys. Metallurgical and Materials Transactions A, 40, 1588-1603. https://doi.org/10.1007/s11661-009-9858-5

[24] Lutjering, G. and Williams, J.C. (2007) Titanium. 2nd Edition, Springer, Berlin.

[25] Lin, Y.C., Yin, L.X., Luo, C.S., He, G.D. and Peng, B.X. (2018) Effects of Initial $\delta$ Phase on Creep Behaviors and Fracture Characteristics of a Nickel-Based Superalloy. Advanced Engineering Materials, 20, Article ID: 1700820.

https://doi.org/10.1002/adem.201700820

[26] Lin, Y.C., Li, L., He, D.G., Chen, M.S., Liu, G.Q. and Guo, Q. (2017) Effects of Pre-Treatments on Mechanical Properties and Fracture Mechanism of a NickelBased Superalloy. Materials Science and Engineering: A, 679, 401-409. https://doi.org/10.1016/j.msea.2016.10.058

[27] Shore, F.M., Morakabati, M., Abbasi, S.M. and Momeni, A. (2014) Hot Deformation Behavior of Incoloy 901 through Hot Tensile Testing. Journal of Materials Engineering and Performance, 23, 1424-1433. https://doi.org/10.1007/s11665-014-0863-5

[28] Rao, G.A., Kumar, M., Srinivas, M. and Sarma, D.S. (2003) Effect of Standard Heat Treatment on the Microstructure and Mechanical Properties of Hot Isostatically Pressed Superalloy Inconel 718. Materials Science and Engineering. A, 355, 114125. https://doi.org/10.1016/S0921-5093(03)00079-0

[29] Shore, F.M., Morakabati, M., Abbasi, S.M., Momeni, A. and Mahdavi, R. (2014) Hot Ductility of Incoloy 901 Produced by Vacuum Arc Remelting. ISIJ International, 54, 1353-1360. https://doi.org/10.2355/isijinternational.54.1353 
[30] Kaupp, G. (2020) Indentation onto Stishovite $\left(\mathrm{SiO}_{2}\right), \mathrm{MgO}$, and a Covered Superalloy: "Pop-In" Repair, Phase-Transition Onsets, Polymorph Energies, and TransitionEnergies. Advances in Materials Physics and Chemistry, 10, 77-95.

https://doi.org/10.4236/ampc.2020.103007 